\title{
Transport processes at quartz-water interfaces: constraints from hydrothermal grooving experiments
}

\author{
K. Klevakina ${ }^{1}$, J. Renner ${ }^{1}$, N. Doltsinis ${ }^{2, *}$, and W. Adeagbo ${ }^{2, * *}$ \\ ${ }^{1}$ Institut für Geologie, Mineralogie und Geophysik, Ruhr-Universität Bochum, 44780 Bochum, Germany \\ ${ }^{2}$ Institut für Chemie, Ruhr-Universität Bochum, 44780 Bochum, Germany \\ *now at: Institut für Festkörpertheorie, Westfälische Wilhelms-Universität, 48149 Münster, Germany \\ ** now at: Institut für Physik, Martin-Luther-Universität Halle-Wittenberg, 06120 Halle, Germany \\ Correspondence to: J. Renner (joerg.renner@rub.de)
}

Received: 25 March 2013 - Published in Solid Earth Discuss.: 22 April 2013

Revised: 30 June 2014 - Accepted: 22 July 2014 - Published: 27 August 2014

\begin{abstract}
We performed hydrothermal annealing experiments on quartzite samples at temperatures of 392 to $568{ }^{\circ} \mathrm{C}$ and fluid pressures of 63 to $399 \mathrm{MPa}$ for up to $120 \mathrm{~h}$, during which hydrothermal grooves developed on the free surfaces of the samples. An analysis of surface topology and groove characteristics with an atomic force microscope revealed a range of surface features associated with the simultaneous and successive operation of several processes partly depending on crystal orientation during the various stages of an experiment. Initially, dissolution at the quartzite-sample surface occurs to saturate the fluid in the capsule with $\mathrm{SiO}_{2}$. Subsequently, grooving controlled by diffusion processes takes place parallel to dissolution and precipitation due to local differences in solubility. Finally, quench products develop on grain surfaces during the termination of experiments. The average groove-root angle amounts to about $160^{\circ}$, varying systematically with misorientation between neighboring grains and depending slightly on temperature and run duration. The grooving is thermally activated, i.e., groove depth ranging from $5 \mathrm{~nm}$ to several micrometers for the entire suite of experiments generally increases with temperature and/or run time. We use Mullins' classical theories to constrain kinetic parameters for the transport processes controlling the grooving. In the light of previous measurements of various diffusion coefficients in the system $\mathrm{SiO}_{2}-\mathrm{H}_{2} \mathrm{O}$, interface diffusion of $\mathrm{Si}$ is identified as the most plausible rate-controlling process. Grooving could potentially proceed faster by diffusion through the liquid if the fluid were not convecting in the capsule. Characteristic times of healing of microfractures in hydrous environments constrained from these kinetic parame-
\end{abstract}

ters are consistent with the order of magnitude of timescales over which postseismic healing occurs in situ according to geophysical surveys and recurrence intervals of earthquakes.

\section{Introduction}

Quartz-filled veins of hydrothermal origin are common in rocks (e.g., Hilgers and Urai, 2002; Urai et al., 1991), documenting that $\mathrm{SiO}_{2}$ is temporarily mobilized in the presence of water. The quantitative description of dissolution, precipitation, and transport processes in the system $\mathrm{SiO}_{2}-\mathrm{H}_{2} \mathrm{O}$ is thus relevant for a general understanding of mass and energy transport in the earth's crust, and specifically, of the creation and sealing of fluid conduits requiring experimental determination of various kinetic parameters (see for example Lasaga and Blum, 1986). Consequently, the thermodynamics of quartz-water mixtures have been the subject of research for at least half a century, leading to constraints on solubility and dissolution kinetics of quartz in hydrous fluids (e.g., Gerya et al., 2005; Manning, 1994; Tester et al., 1994; Weill and Fyfe, 1964) as well as diffusion coefficients of silicon and oxygen in water and in quartz along different diffusion paths (e.g., Doltsinis et al., 2007a, b; Farver and Yund, 2000, 1995, 1991; Joesten and Fisher, 1988; Milke and Heinrich, 2002).

Grooves are a surface feature of polycrystalline aggregates that occur in order to minimize surface energy. In material science, grooving studies have proven to be a valuable source for interface kinetic parameters (e.g., Mullins and Shewmon, 
1959; Rabkin et al., 2006). The evolution of grooves is controlled by the transport and/or dissolution/precipitation kinetics of constituents. For the first time, the relation between the dominating diffusion process and groove geometry was formulated by Mullins (1960, 1957). Previous experimental studies on grooving characteristics were mostly performed on metals and alloys (Mullins and Shewmon, 1959; Rabkin et al., 2006; Rabkin et al., 2001) but some observations were reported for oxide ceramics (Saylor and Rohrer, 1999) and minerals (Hay and Evans, 1983; Peters and Reimanis, 2003).

The objective of our exploratory study is to experimentally constrain the rate-controlling step and the dominant transport mechanism for mobilization and deposition of $\mathrm{SiO}_{2}$ at quartz-water interfaces at conditions relevant for the earth's upper crust. To this end, we investigated hydrothermal grooving at the interface of quartz aggregates and water by analyzing geometrical groove characteristics as a function of time, temperature and pressure.

\section{Background}

\subsection{Thermal grooving}

When grain boundaries intersect an aggregate's surface, grooves tend to form due to the minimization of interface energy. The geometry of the groove root is determined by the balance of the two surface tensions: the grain boundary tension, and the constraint from the boundary tilt with respect to the free surface (Hackl et al., 2012; Herring and Conyers, 1951). In the case that surface properties are independent of the orientation of the crystals, the following relation holds for the two angles at the root (Fig. 1):

$$
\frac{\gamma_{\mathrm{gb}}}{\gamma_{\mathrm{s}}}=\cos \alpha_{1}+\cos \alpha_{2}
$$

with $\gamma_{\mathrm{gb}}$ and $\gamma_{\mathrm{s}}$ denoting grain boundary energy and surface energy, respectively (Hackl et al., 2012). For grain boundaries intersecting the surface at a normal angle, we have $\alpha_{1}=\alpha_{2}$, and half of the total root angle $\alpha \equiv \alpha_{1}+\alpha_{2}$ coincides with the dihedral angle $\psi$, defined as

$\cos (\psi)=\frac{\gamma_{\mathrm{gb}}}{2 \gamma_{\mathrm{s}}}$

and commonly used as a quantification of the ratio between grain boundary energy and surface energy (e.g., Bailey and Watkins, 1950; Rabkin et al., 2001). Unfortunately, the use of the term dihedral angle lacks consistency; for example, Holness (1992) denotes the total enclosed angle as a dihedral angle rather than half of it.

Equation (1) does not describe a stable equilibrium state, but grooves will deepen with time while maintaining their geometrical characteristics. The actual surface evolution can be controlled by the kinetics of different atomistic transport processes. Mullins $(1960,1957)$ investigated grooving as controlled by the following diffusion paths: (a) through the grain

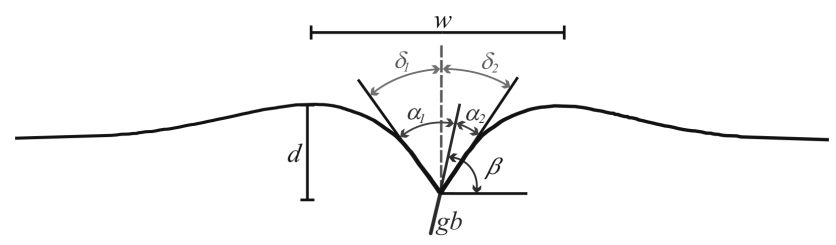

Figure 1. Sketch illustrating the parameters characterizing groove geometry. The distance between humps is termed groove width $w$, the distance between groove root and a hump is termed groove depth $d$. The grain boundary ( $\mathrm{gb}$ ) encloses an angle $\beta$ with the surface of the polycrystal and the two sides of the groove are inclined by angles $\delta_{1,2}$ to the surface's normal.

volume, (b) through the stagnant liquid in contact with the solid, and (c) along the solid-liquid interface, i.e., the grains' surfaces. In addition, grooving by dissolution/evaporation was analyzed (Bokstein et al., 1995; Mullins, 1957). These early analyses were performed for monatomic materials with isotropic surface energy, dihedral angles independent of annealing time, and grain boundaries normal to the surface. The analytical solutions were derived by employing a small-slope approximation yield self-similar evolution of groove geometry, expressed by groove depth $d$ and groove width $w$ (Fig. 1) according to

$d(t)=\lambda_{i, d} \cot \alpha\left(B_{i} t\right)^{1 / n}$

and

$w(t)=\lambda_{i, w}\left(B_{i} t\right)^{1 / n}$,

where $t$ denotes time. The parameters $B_{i}$ and $\lambda_{i}(i=\mathrm{v}, 1, \mathrm{~s}$ for diffusion through the solid volume, the liquid, and along the surface of the solid, respectively) depend on the dominant diffusion path (see Table 1). In particular, $\lambda_{w} / \lambda_{d}$ amounts to 4.95 and 4.73 for $n=3$ and 4 (i.e., diffusion through the liquid and along the interface), respectively. Notably, the theory suggests that the occurrence and absence of humps on both sides of the grain boundary helps to discern between diffusion-controlled and dissolution-controlled grooves.

A number of analytical and numerical approaches extended Mullins' seminal work by considering large slopes (Robertson, 1971), anisotropy of surface energies (Zhang et al., 2004), tilted grain boundaries (Hackl et al., 2012; Min and Wong, 2006), diffusion in a multicomponent system (Dhalenne et al., 1979; Klinger, 2002), and the effect of mobile crystal defects (Rabkin et al., 2001). The geometry of the groove is sensitive to these extensions but general features of the Mullins' theory are mostly maintained while the absolute grooving kinetics are altered. When multicomponent diffusion (Dhalenne et al., 1979; Klinger, 2002) takes place or time dependence of interface energies is involved (Zhang et al., 2002), the growth exponent $n$ may change considerably. 
Table 1. Parameters of analytical models for grooving following the generic Eq. (3) and (4) controlled by the listed diffusion processes (see 1960; Mullins, 1957).

\begin{tabular}{llll}
\hline Diffusion process & Exponent & $B_{i}$ & $\lambda_{i}$ \\
\hline Diffusion through the solid & $n=3$ & $B_{\mathrm{V}}=\frac{D_{\mathrm{v}} \gamma_{\mathrm{s}} \Omega}{k_{\mathrm{B}} T}$ & $\lambda_{\mathrm{v}, d}=1.01, \lambda_{\mathrm{v}, w}=5$ \\
Diffusion through the liquid & $n=3$ & $B_{1}=\frac{D_{\mathrm{l}} C_{0} \gamma_{\mathrm{s}} \Omega^{2}}{k_{\mathrm{B}} T}$ & $\lambda_{1, d}=1.01, \lambda_{1, w}=5$ \\
Diffusion along the interface of solid and liquid & $n=4$ & $B_{\mathrm{S}}=\frac{D_{\mathrm{s}} \gamma_{\mathrm{\gamma}} \Omega \delta}{k_{\mathrm{B}} T}$ & $\lambda_{\mathrm{s}, d}=0.973, \lambda_{\mathrm{s}, w}=4.6$ \\
\hline
\end{tabular}

$B_{i}, \lambda_{i}$ See Eqs. (3), (4).

$\Omega$ Molecular (atomic) volume $\left(1.13 \times 10^{-28} \mathrm{~m}^{3}\right)$

$\gamma_{\mathrm{S}}$ Surface-free energy per unit area $\left(1 \mathrm{~J} \mathrm{~m}^{-2}\right)$.

$\delta$ Thickness of the layer in which surface diffusion takes place $(2 \mathrm{~nm})$.

$k_{\mathrm{B}}$ Boltzman constant $\left(1.38 \times 10^{-23} \mathrm{~J} \mathrm{~K}^{-1}\right)$.

$D_{i}$ Diffusion coefficient $D_{i}=D_{0, i} \exp \left(-E_{i}+p V_{i} / R T\right)$ with activation energy $E_{i}$, activation volume $V_{i}$, and universal gas constant $R$

$\left(8.31 \mathrm{~J} \mathrm{~mol}^{-1} \mathrm{~K}^{-1}\right)$; the subscript $i=\mathrm{v}, 1$, s serves as an indicator of the diffusion path (v: volume diffusion in solid, l: diffusion in liquid, $\mathrm{s}$ : diffusion along surface).

$C_{0}$ Equilibrium concentration $C_{0}=m_{\mathrm{H}_{4}}^{\mathrm{sat}} \mathrm{SiO}_{4} N_{\mathrm{A}} / V(p, T)$ of solute in the solvent; varies from $1.2 \times 10^{25}$ to $5.0 \times 10^{25}$ number of molecules

per $\mathrm{m}^{3}$ depending on run temperature and pressure and was calculated from $m_{\mathrm{H}_{4}}^{\mathrm{sat}} \mathrm{SiO}_{4}$, see Eq. (5) and Table 2, Avogadro's constant

$N_{\mathrm{A}}=6 \times 10^{23} \mathrm{~mol}^{-1}$, and the specific volume of water $V(p, T)$ obtained using the software package FLUIDCAL,

http://www.ruhr-uni-bochum.de/thermo/Software/Seiten/Fluidcal-eng.htm (Wagner and Pruß, 2002).

$n$ Growth exponent.

\subsection{Solubility of $\mathrm{SiO}_{2}$ in water and associated dissolution kinetics}

The solubility of quartz in aqueous fluids is an important geochemical parameter and plays a major role both for planning our experiments and for their evaluation. At the start of an experiment, capsule charges consisting of a quartzite sample and distilled water are in disequilibrium. With time, equilibrium is achieved by dissolution of the solid. Several questions have to be answered with respect to their consequences for groove evolution. (a) How much $\mathrm{SiO}_{2}$ goes into the solution and at what stage in a course of an experiment? (b) After what time is equilibrium reached at $p-T$-conditions? (c) Is the liquid likely to be stagnant in the capsule? The quantitative constraints on solubility and dissolution kinetics of quartz in water are therefore reviewed first and then the potential for convection in our capsules is analyzed.

\subsubsection{Solubility of $\mathrm{SiO}_{2}$ in water}

The solubility of quartz in water and its dependence on temperature and pressure have been a subject of a number of experimental studies since the 1940s (e.g., Fyfe and McKay, 1962; Gerya et al., 2005; Gratz and Bird, 1993b; Morey et al., 1962; Weill and Fyfe, 1964). The solution of quartz in water was thought to proceed congruently and reversibly according to $\mathrm{SiO}_{2(\mathrm{~s})}+2 \mathrm{H}_{2} \mathrm{O}_{(\mathrm{aq})} \leftrightarrow \mathrm{H}_{4} \mathrm{SiO}_{4(\mathrm{aq})}$ (Manning, 1994). More recent work, however, indicates that polymerization of the silicic acid product may be significant for the dissolution process (Doltsinis et al., 2007a, b; Gerya et al., 2005). We rely on the quantitative description by Fournier and Potter (1982) to describe the concentration at saturation, $m_{\mathrm{H}_{4} \mathrm{SiO}_{4}}^{\mathrm{sat}}$ $\left(\mathrm{mol}_{\mathrm{SiO}_{2}} \mathrm{~kg}_{\mathrm{H}_{2} \mathrm{O}}{ }^{-1}\right)$, as a function of absolute temperature $T$ and pressure $p$ by

$\log _{10} m_{\mathrm{H}_{4} \mathrm{SiO}_{4}}^{\mathrm{sat}}=A+B \log _{10} V+C\left(\log _{10} V\right)^{2}$,

with $A=-4.66206+0.0034063 T+2179.7 T^{-1}-1.1292 \times$ $10^{6} T^{-2}+1.3543 \times 10^{87} T^{-3}, \quad B=-0.00147180 T-$ $806.97 T^{-1}, C=3.9465 \times 10^{-4} T$, and $V(p, T)\left(\mathrm{cm}^{3} \mathrm{~g}-1\right)$ denoting the specific volume of water. The more recent quantitative relation by Gerya et al. (2005) yields modest deviations from Eq. (5) for our test conditions and we preferred Eq. (5) in order to use a consistent source for solubility and dissolution kinetics (see below).

\subsubsection{Dissolution kinetics of $\mathrm{SiO}_{2}$ in water}

On the basis of a large experimental data set, Tester et al. (1994) derived the kinetics of quartz dissolution in water as

$m(t)=m_{\mathrm{H}_{4} \mathrm{SiO}_{4}}^{\mathrm{sat}}-\left(m_{\mathrm{H}_{4} \mathrm{SiO}_{4}}^{\mathrm{sat}}-m_{\mathrm{H}_{4} \mathrm{SiO}_{4}}^{0}\right) \exp \left(-\frac{k A t}{M m_{\mathrm{H}_{4} \mathrm{SiO}_{4}}^{\mathrm{sat}}}\right)$

with a rate constant of

$k=(276 \pm 193) \exp \left(-\frac{90.1 \pm 2.5 \mathrm{~kJ} \mathrm{~mol}^{-1}}{R T}\right) \frac{\mathrm{mol}_{\mathrm{SiO}_{2}}}{\mathrm{~m}^{2} \mathrm{~s}}$.

"without any attempt to model molecular level phenomena such as the bond-breaking steps that must occur for quartz to enter the aqueous phase as silicic acid" (Tester et al., 1994). In Eq. (6), $A\left(\mathrm{~m}^{2}\right)$ denotes the reactive surface area, $M\left(\mathrm{~kg}_{\mathrm{H}_{2} \mathrm{O}}\right)$ the mass of water, $t$ (s) time, and $m_{\mathrm{H}_{4} \mathrm{SiO}_{4}}^{0}$ the initial concentration of silicic acid $\left(\mathrm{mol}_{\mathrm{SiO}_{2}} \mathrm{~kg}_{\mathrm{H}_{2} \mathrm{O}}{ }^{-1}\right)$. We combined Eqs. (5) to (7) to evaluate the dissolution evolution in 
our experiments using the measured amounts of added water and the total surface area of a sample as active surface area. Calculations accounting for the actual $p-T-t$ evolution of the experiments indicate that equilibrium concentrations should be reached after 2.2 and $0.8 \mathrm{~h}$ at 392 and $568^{\circ} \mathrm{C}$, respectively.

\section{Material and methods}

\subsection{Sample material, experimental apparatus and procedure}

In comparison to grooving studies on metals in controlled gas atmospheres, an investigation of hydrothermal grooving potentially faces several complications due to the kinetics of equilibration between mineral and fluid, and orientation dependence of surface energy and/or diffusion coefficients of a low-symmetry mineral such as quartz. Therefore, we chose an approach employing polycrystalline aggregates with a large number of grain boundaries that terminate at the solid-fluid interface and thus aiming at bulk statistical observations. Specifically, we used quartzite (novaculite from Arkansas, see Keller et al., 1977) with an average grain size of 20 to $30 \mu \mathrm{m}$ in all experiments. Samples were prepared to cylindrical shape with a height of $\sim 4 \mathrm{~mm}$ and a diameter of $\sim 3 \mathrm{~mm}$. One circular end face was sequentially polished to mirror quality first using $\mathrm{SiC}$ paper then diamond oil paste down to $1 \mu \mathrm{m}$ particle size. Two samples (see Table 2) were chemically polished with SITON for orientation analyses with the electron backscatter diffraction (EBSD) technique before the hydrothermal annealing experiments. The carbon coating applied for EBSD analysis was removed by polishing with a soft tissue before the actual annealing experiment. The effect of the polishing procedure on grooving was addressed by preparing a sample with just one-half of its surface experiencing the additional SITON polishing.

Prepared quartzite cylinders were placed in gold capsules, together with 16 to $35 \mu \mathrm{L}$ distilled water. Capsules were welded shut under a binocular. Sealing was checked by heating capsules to $60^{\circ} \mathrm{C}$ and monitoring their weight. Samples were annealed in a hydrothermal apparatus comprising an externally heated vessel. Vessel and capsules were oriented horizontally with their cylindrical axes. The heating rate was controlled to $20^{\circ} \mathrm{C} \mathrm{min}^{-1}$ and the cooling time from 580 to $40^{\circ} \mathrm{C}$ was about $3 \mathrm{~h}$, reaching $300^{\circ} \mathrm{C}$ after less than 24 min. Evaluating Eq. (6) for the employed heating rate indicates that 5 and $50 \%$ of the saturation concentrations were reached, arriving at 392 and $568^{\circ} \mathrm{C}$, respectively.

Typically, samples experienced a single annealing run but some samples were repeatedly re-capsuled after intermittent investigations. We further varied the procedure in several aspects to provide constraints on dissolution processes during our experiments. Some capsules were charged with silica gel or fine quartz powder in addition to the quartzite sample (see
Table 2). These powders are expected to be preferentially dissolved compared to the quartzite.

The calculations regarding the time it takes for the fluid to equilibrate with the quartzite samples (see Sect. 2.2.2) were performed under the assumption that the bulk water is at rest in the capsule. However, when the water convects in the capsule, equilibration may proceed faster. Furthermore, continuous transport of solute from dissolution sites to precipitation sites may then be promoted after bulk equilibration is reached. Calibration runs constrained axial and radial gradients of 1.5 and $0.4{ }^{\circ} \mathrm{C} \mathrm{mm}^{-1}$, respectively, yielding Rayleigh numbers (Siggia, 1994) of $>10^{6}$ for our assembly and strongly suggesting the occurrence of convection.

\subsection{Determination of groove characteristics}

After the hydrothermal annealing, the previously polished end faces of samples were studied by light and atomic force microscopy (AFM, XE-100 PSIA). The AFM measurements were performed in contact mode using cantilevers with a nominal tip radius of $10 \mathrm{~nm}$ (910M-NSC36, 910MSICONA). Generally, square areas of $90 \mu \mathrm{m}$ edge length were scanned, with a frequency between 0.4 and $0.6 \mathrm{~Hz}$ and a grid spacing of $\sim 0.18 \mu \mathrm{m}$. The horizontal step size causes an uncertainty in groove depth of less than $25 \mathrm{~nm}$ for the encountered root angles. With the use of smaller scan areas, a higher lateral resolution can be achieved and thus a better groove depth resolution. However, the chosen area constitutes a reasonable compromise between scan duration and accuracy given that individual grooves vary considerably in their properties.

In the vast majority of cases, geometrical groove characteristics were derived from averaged profiles. Averaging was performed by overlaying the groove trace with a rectangle, with its long edges parallel to the trace and all perpendicular transects stacked within the rectangle. The variability of the groove characteristics within a chosen rectangle can be substantial, i.e., $\pm 50 \%$ in depth. This large variability results mostly from blunt roots, possibly due to precipitated quench materials. In less than $10 \%$, we had to rely on single scan profiles for the determination of depth, width, and grooveroot angle because averaging failed due to poor surface quality. The quoted average groove characteristics are considered reliable representations of the depth and the groove-root angle to within about $\pm 15 \%$ and $\pm 5^{\circ}$, respectively. The effects of scan direction (relative to groove) and frequency do not further increase the uncertainty in groove characteristics. Results represent averages and standard deviations for the averaged parameters gained from investigating up to 600 grooves for a single sample (Table 2).

\subsection{Grain orientation analysis}

The orientation of individual grains relative to the sample surface and to their neighbors (misorientation) was 
Table 2. Conditions and results of the conducted hydrothermal annealing experiments.

\begin{tabular}{|c|c|c|c|c|c|c|c|c|c|}
\hline Sample & $\begin{array}{r}T \\
\left({ }^{\circ} \mathrm{C}\right)\end{array}$ & $\begin{array}{r}p \\
(\mathrm{MPa})\end{array}$ & $\begin{array}{r}t \\
(\mathrm{~h})\end{array}$ & $\begin{array}{r}m_{\text {sat }} \\
\left(\mathrm{mol}_{\mathrm{SiO}_{2}}\right. \\
\mathrm{kg}_{\left.\mathrm{H}_{2} \mathrm{O}^{-1}\right)}\end{array}$ & $\begin{array}{r}\alpha \\
\left(^{\circ}\right)\end{array}$ & $\begin{array}{l}d_{\max } \\
(\mathrm{nm})\end{array}$ & $\begin{array}{l}\delta_{1} \\
\left(^{\circ}\right)\end{array}$ & $\begin{array}{l}d_{\min } \\
(\mathrm{nm})\end{array}$ & $\begin{array}{l}\delta_{2} \\
\left(^{\circ}\right)\end{array}$ \\
\hline \multicolumn{10}{|c|}{ Sequential experiments } \\
\hline $\mathrm{P} 40$, run 1 & 392 & 200 & 5.7 & 0.0382 & $166 \pm 12(52)^{\dagger}$ & $179 \pm 121(178)$ & $84 \pm 3(65)$ & $22 \pm 41(178)$ & $87 \pm 2(62)$ \\
\hline run 2 & 392 & 198 & 3 & 0.0381 & $160 \pm 12(86)$ & $385 \pm 314(189)$ & $79 \pm 5(94)$ & $116 \pm 276(186)$ & $82 \pm 9(96)$ \\
\hline run 3 & 392 & 177 & 2 & 0.0365 & $145 \pm 44(4)$ & $684 \pm 455(13)$ & $81 \pm 3(6)$ & $168 \pm 169(12)$ & $84 \pm 3(7)$ \\
\hline $\mathrm{P} 43$, run 1 & 441 & 198 & 4 & 0.0520 & nd & nd & nd & nd & nd \\
\hline run 2 & 490 & 199 & 21.8 & 0.0686 & $146 \pm 18(79)$ & $597 \pm 295(77)$ & $71 \pm 10(79)$ & $407 \pm 220(79)$ & $76 \pm 10(79)$ \\
\hline \multicolumn{10}{|c|}{ Experiments with added $\mathrm{SiO}_{2}$ powder } \\
\hline P36 & 392 & 209 & 24 & 0.0388 & $169 \pm 4(20)$ & $144 \pm 109(86)$ & $83 \pm 2(20)$ & $38 \pm 33(86)$ & $85 \pm 3(20)$ \\
\hline P32 & 490 & 200 & 8 & 0.6870 & $144 \pm 33(27)$ & $957 \pm 696(96)$ & $76 \pm 16(27)$ & $252 \pm 251(97)$ & $80 \pm 5(23)$ \\
\hline \multicolumn{10}{|c|}{ Single condition experiments } \\
\hline $\mathrm{P} 47 *$ & 392 & 194 & 7.5 & 0.0377 & $166 \pm 14(121)$ & $80 \pm 48(244)$ & $83 \pm 5(133)$ & $27 \pm 31(244)$ & $85 \pm 5(123)$ \\
\hline P22 & 392 & 63 & 24 & 0.0239 & $175 \pm 3(69)$ & $45 \pm 26(134)$ & $86 \pm 9(101)$ & $26 \pm 14(134)$ & $88 \pm 1(100)$ \\
\hline P11 & 392 & 198 & 24 & 0.0380 & $172 \pm 4(99)$ & $119 \pm 77(403)$ & $85 \pm 3(124)$ & $43 \pm 36(403)$ & $86 \pm 2(113)$ \\
\hline $\mathrm{P} 44^{*}$ & 392 & 202 & 24 & 0.0370 & $169 \pm 5(126)$ & $119 \pm 80(247)$ & $83 \pm 3(137)$ & $38 \pm 29(247)$ & $84 \pm 10(134)$ \\
\hline P23 & 392 & 399 & 24 & 0.0492 & $171 \pm 5(59)$ & $133 \pm 68(113)$ & $84 \pm 10(79)$ & $68 \pm 45(108)$ & $84 \pm 14(81)$ \\
\hline P57* & 392 & 201 & 48 & 0.0381 & $164 \pm 5(156)$ & $123 \pm 50(186)$ & $81 \pm 7(158)$ & $88 \pm 35(186)$ & $83 \pm 3(157)$ \\
\hline $\mathrm{P} 51^{*}$ & 392 & 98 & 72 & 0.0286 & $166 \pm 5(45)$ & $103 \pm 29(46)$ & $82 \pm 4(46)$ & $76 \pm 28(46)$ & $84 \pm 3(45)$ \\
\hline P10 & 392 & 194 & 72 & 0.0378 & $157 \pm 14(187)$ & $327 \pm 144(322)$ & $78 \pm 6(225)$ & $219 \pm 95(322)$ & $80 \pm 5(217)$ \\
\hline P53* & 392 & 292 & 72 & 0.0451 & $160 \pm 15(47)$ & $190 \pm 127(50)$ & $79 \pm 5(49)$ & $91 \pm 77$ (49) & $82 \pm 5(47)$ \\
\hline $\mathrm{P} 45^{*}$ & 392 & 198 & 96 & 0.0381 & $155 \pm 19(134)$ & $213 \pm 155(159)$ & $77 \pm 9(148)$ & $150 \pm 138(159)$ & $79 \pm 9(136)$ \\
\hline $\mathrm{P} 20$ & 392 & 188 & 120 & 0.0373 & $172 \pm 4(28)$ & $199 \pm 173(54)$ & $85 \pm 3(46)$ & $108 \pm 71(46)$ & $86 \pm 3(40)$ \\
\hline P37 & 441 & 203 & 2 & 0.0527 & $159 \pm 10(70)$ & $228 \pm 151(148)$ & $78 \pm 5(72)$ & $90 \pm 88(148)$ & $81 \pm 6(71)$ \\
\hline $\mathrm{P} 25$ & 441 & 200 & 8 & 0.0524 & $168 \pm 7(80)$ & $113 \pm 60(127)$ & $82 \pm 5(94)$ & $65 \pm 41(127)$ & $85 \pm 3(97)$ \\
\hline P27 & 441 & 200 & 24 & 0.0523 & $159 \pm 16(139)$ & $193 \pm 105(192)$ & $79 \pm 8(157)$ & $134 \pm 77$ (192) & $81 \pm 4(158)$ \\
\hline P17 & 441 & 202 & 72 & 0.0526 & $126 \pm 18(8)$ & $3125 \pm 871(11)$ & $65 \pm 10(10)$ & $2803 \pm 1041$ & $61 \pm 12(10)$ \\
\hline $\mathrm{P} 8$ & 490 & 198 & 2 & 0.0680 & $169 \pm 5(88)$ & $126 \pm 63(397)$ & $84 \pm 3(108)$ & $45 \pm 34(397)$ & $85 \pm 3(116)$ \\
\hline $\mathrm{P} 12$ & 490 & 208 & 8 & 0.0702 & $162 \pm 12(195)$ & $188 \pm 98(298)$ & $79 \pm 12(239)$ & $109 \pm 69(298)$ & $82 \pm 7(218)$ \\
\hline P15 & 490 & 192 & 72 & 0.0670 & $162 \pm 10(18)$ & $594 \pm 382(24)$ & $80 \pm 7(19)$ & $359 \pm 188(23)$ & $81 \pm 5(20)$ \\
\hline $\mathrm{P} 48^{*}$ & 568 & 200 & 0.09 & 0.0989 & $157 \pm 13(27)$ & $250 \pm 116(61)$ & $77 \pm 6(29)$ & $74 \pm 81(61)$ & $80 \pm 8(27)$ \\
\hline P30 & 568 & 64 & 2 & 0.0181 & $166 \pm 7(168)$ & $110 \pm 36(189)$ & $83 \pm 3(175)$ & $76 \pm 30(188)$ & $83 \pm 7(175)$ \\
\hline $\mathrm{P} 42^{*}$ & 568 & 204 & 4 & 0.1003 & $167 \pm 7(107)$ & $390 \pm 178(157)$ & $83 \pm 5(120)$ & $146 \pm 93(157)$ & $85 \pm 4(116)$ \\
\hline P21 & 568 & 202 & 8 & 0.0997 & $159 \pm 18(73)$ & $461 \pm 182(263)$ & $80 \pm 6(120)$ & $307 \pm 133(263)$ & $81 \pm 4(109)$ \\
\hline $\mathrm{P} 50^{*}$ & 568 & 100 & 24 & 0.0455 & $135 \pm 18(91)$ & $469 \pm 256(94)$ & $67 \pm 10(91)$ & $366 \pm 230(92)$ & $69 \pm 10(91)$ \\
\hline P46* & 568 & 205 & 24 & 0.1007 & $138 \pm 23(112)$ & $937 \pm 529(28)$ & $67 \pm 13(116)$ & $754 \pm 479$ (128) & $70 \pm 12(115)$ \\
\hline P54 & 568 & 260 & 47.7 & 0.1203 & & & nd & & \\
\hline P38 & 568 & 202 & 48 & 0.0996 & $144 \pm 14(116)$ & $738 \pm 383(203)$ & $72 \pm 9(120)$ & $578 \pm 348(203)$ & $72 \pm 8(118)$ \\
\hline
\end{tabular}

Temperature, pressure, and duration of an annealing run are denoted $T, p$, and $t$, respectively; the equilibrium concentration $m_{\mathrm{H}_{4}}^{\text {sat }} \mathrm{SiO}_{4}$ was calculated according to Eq. (5).

$\dagger$ Groove characteristics (see Fig. 1), root angle $\alpha$, larger and smaller groove depth, $d_{\max }$ and $d_{\min }$, and corresponding half-root angles, $\delta_{1}$ and $\delta_{2}$, are reported as arithmetic mean and standard deviation with the number of observations in parentheses.

* Samples used to calculate the kinetic parameters activation volume, activations energy, diffusion coefficient $D_{i}, E_{i}, V_{i}$ (see Table 2).

determined by the electron backscatter diffraction (EBSD) technique, using an LEO 1530 scanning electron microscope (SEM) with a field emission gun. The SEM was operated at an accelerating voltage of $20 \mathrm{kV}$ with a working distance of $25 \mathrm{~mm}$ from the sample surface and tilted at an angle of $70^{\circ}$. Indexing and processing was performed by the CHANNEL5 HKL software. The misorientation between individual grains was determined with Stereo32. Here we restrict ourselves to characterizing only pairs of grains for which a single angle expresses the associated misorientation. The relation between neighboring grains that both exhibit $c$ axes nor- mal to their surfaces (within $\pm 10^{\circ}$ ) is expressed by the angle enclosed by the two $a$ axes. Grains with either the $a$ axis or the $b$ axis normal to their surface (within $\pm 10^{\circ}$ ) are characterized by the angle enclosed by their $c$ axes.

\section{Experimental results}

A total of 25 "standard" annealing experiments were performed at temperatures of $392,441,490$, and $568^{\circ} \mathrm{C}$ and pressures from 63 to $399 \mathrm{MPa}$ for durations up to $120 \mathrm{~h}$ (Table 2). In addition, we ran two sequential anneals, three 


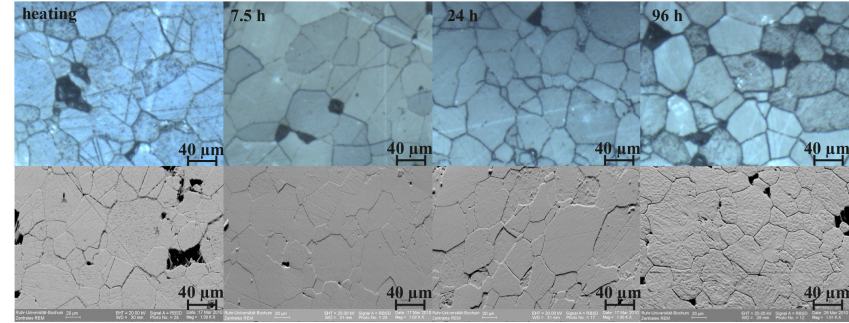

Figure 2. Sample surfaces as observed with a light microscope (top row) and SEM (bottom row) for samples annealed at $392^{\circ} \mathrm{C}$ for 7.5 , 24 , and $96 \mathrm{~h}$. The images labeled heating show a sample that experienced heating up to $568^{\circ} \mathrm{C}$ at $200 \mathrm{MPa}$ and immediate cooling.

experiments with added powders, and one with altered sample geometry (P38). Groove formation is already visible using the light microscope (Fig. 2). Yet, the initially flat and mirror-quality polished surfaces additionally exhibit scratches, significant topography due to grains at different heights, pocks, and holes, and roughness of individual grains after annealing (Fig. 3). In some cases, individual grain surfaces are not parallel to the general sample surface but tilted. The frequency with which these morphological features occur varies with annealing conditions as detailed below; groove characteristics are then reported in relation to experimental conditions.

Groove development and evolution of step height between neighboring grains are affected by polishing treatment and the addition of quartz powder or gel. Experiments on SITONpolished samples with added powders tend to yield surfaces with more pronounced roughness than experiments on SITON-polished samples without added powder. Qualitatively, we do not find a significant difference in surface characteristics of samples that experienced a single anneal and samples that were repeatedly annealed with intermittent quenching for AFM analysis. For the latter, individual grooves could be tracked over a sequence of as much as three annealing steps. The number of tractable grooves is limited by the plug-out of grains and increasing surface roughness. The observations for experiments that performed at the highest temperature of $568^{\circ} \mathrm{C}$ are not obviously exceptional, but extend the trends seen for the experiments at lower temperatures, despite the proximity to the equilibrium line of the low to high quartz transition.

\subsection{Morphology of grain surfaces}

Scratch traces are prominent after the shortest annealing times, indicating that the polishing procedure fills surface irregularities with highly soluble material (Fig. 3a). Scratches tend to occur on high-lying grains after short annealing times, while scratches occur preferentially on low-lying grains after extended annealing. The depth of individual scratches, and consequently the number of scratch traces, decrease with increasing annealing duration and temperature. It is likely that
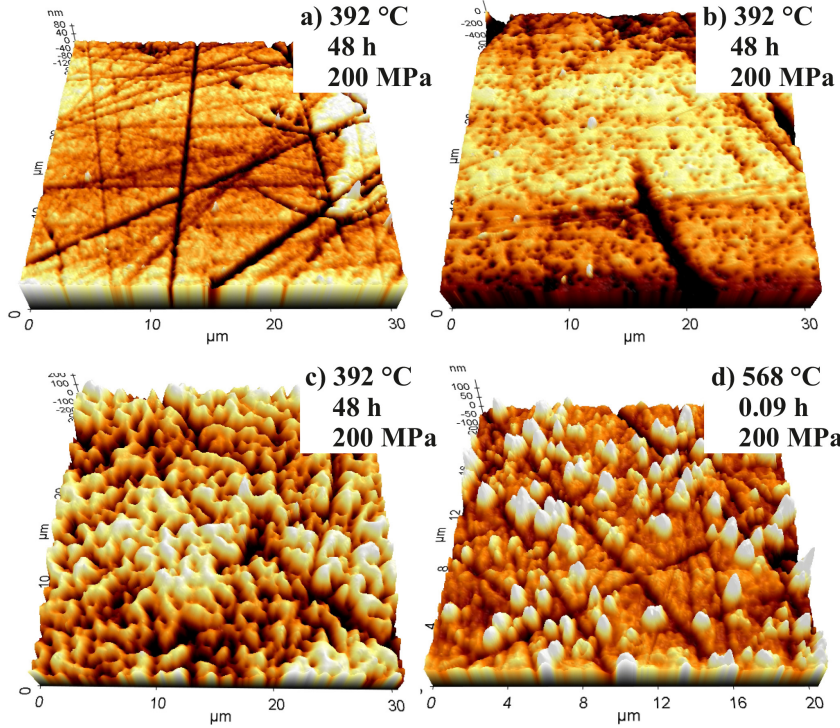

Figure 3. General surface characteristics of hydrothermally annealed samples as observed with AFM. The images represent dissolution (first row) and growth structures (second row) for different crystallographic surfaces. (a) (1010) surface with scratches of different depths up to $70 \mathrm{~nm}$; (b) (1011) surface with holes (10 to $50 \mathrm{~nm}$ ). Growth structure: (c) selected pocks with partly idiomorphic shapes found at low-lying grains of a sample that did not experience extended hydrothermal annealing after reaching the indicated run conditions (P48, see Table 2), (d) (0001) surface with strong roughness found at high-lying grains (relief differences range from 100 to $200 \mathrm{~nm}$ ). The images (a), (b) and (d) represent measurements of a single sample (P57, see Table 2).

this healing, driven by surface energy reduction, proceeds by local transport processes.

With extended annealing, pocks and pits are typically present on low- and high-lying grains, respectively. The large number of closely spaced pocks (Fig. 3d) and holes, partly resembling dislocation etch pits (Fig. 3b), lets individual grains appear roughened at their surface.

Several microstructural features depend on the orientation of individual grains. The SEM images of samples annealed at $568^{\circ} \mathrm{C}$ document the growth of surfaces, with specific orientations yielding the typical habitus of hydrothermally grown quartz crystals (Fig. 4).

To specify the relationship between surface orientation and surface structure, two samples were scanned with EBSD before annealing (see Table 2). We focused on three low-index surfaces, $(0001) \equiv c,(10 \overline{1} 0) \equiv b$, and $(11 \overline{2} 0) \equiv a$, and defined different grain boundary types between neighboring grains with one of these axes perpendicular to the surface within $\pm 10^{\circ}$, in other words, " $a / c$ boundary" is a boundary between two grains, one with the $a$ axis and one with the $c$ axis approximately perpendicular to the surface. The two samples differ in surface structure and height variations of grains. For the experiment run at $392^{\circ} \mathrm{C}$ (P57, Table 2), 


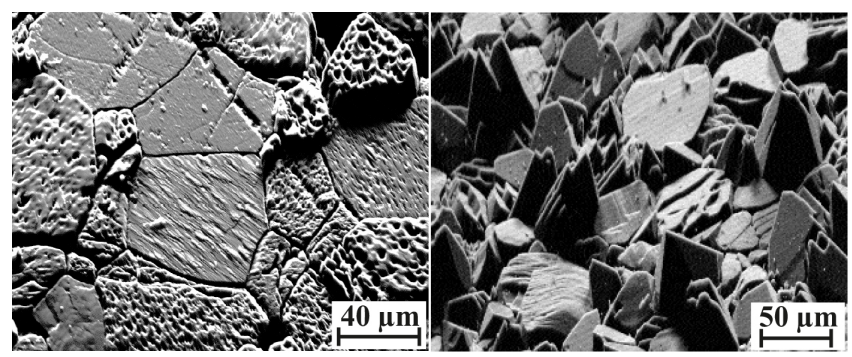

Figure 4. SEM images indicate differences in development of specific crystallographic surfaces for samples annealed at $568^{\circ} \mathrm{C}$ and $260 \mathrm{MPa}$ for $47.7 \mathrm{~h}$ (left) and at $441^{\circ} \mathrm{C}$ and $195 \mathrm{MPa}$ for $72 \mathrm{~h}$ (right). The idiomorphic tips likely indicate the orientation of $c$ axes.

the (0001) surfaces show pronounced roughness and constitute the relatively high-lying surfaces, while the prism surfaces $(10 \overline{10})$ appear relatively low, yet smooth with just a few scratches (Fig. 5a to c). The relative height of (0001) and $(10 \overline{10})$ surfaces is inverse for the experiment run at the higher temperature of $568^{\circ} \mathrm{C}(\mathrm{P} 42$, Fig. $5 \mathrm{~d}$ to f). At this temperature, the majority of grain surfaces are flat and scratches are absent.

\subsection{Groove characteristics}

Grooves exhibit a range of geometries even in a single experiment (Fig. 6a). We find grooves with and without steps (i.e., differences in height between neighboring grains) as well with and without the humps typical for diffusion-controlled groove evolution. We did not develop strict criteria but visual inspection and exemplary statistics suggest the following typical inventory. The shape of about $15 \%$ of the grooves is so biased by surface roughness of the enclosing grains that a characterization is impossible. Of the remaining grooves, 10 to $20 \%$ exhibit clearly visible humps and $<10 \%$ would be characterized as dissolution grooves (Fig. 7). About half of all grooves are of mixed/intermediate character, that is, steps and tilting make characterization difficult. This inventory is rather insensitive to annealing conditions.

Asymmetry of grooves results from steps as well as differences in the half-root angles $\delta_{i}$ (Fig. 1). The larger asymmetry of grooves for $a / c$ boundaries compared with $a / b$ boundaries points toward an orientation dependence of dissolution and growth (affecting step height) but also of interface energy (affecting half-root angle in addition to grain boundary tilt).

\subsubsection{Depth}

Groove depth scatters considerably for a single experiment. The frequency distributions of groove depths typically exhibit a maximum at the smallest depth bin and a continuous decrease towards deeper grooves. Despite the variability of groove morphology for an individual sample, the average groove depth systematically increases with an increase

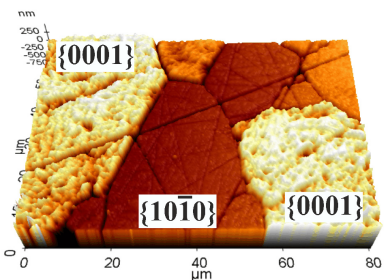

a) $392{ }^{\circ} \mathrm{C}, 48 \mathrm{~h}$

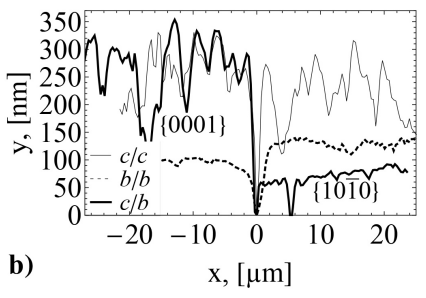

d) $5688^{\circ} \mathrm{C}^{20}, 4 \mathrm{~h} \quad \mu \mathrm{m}$
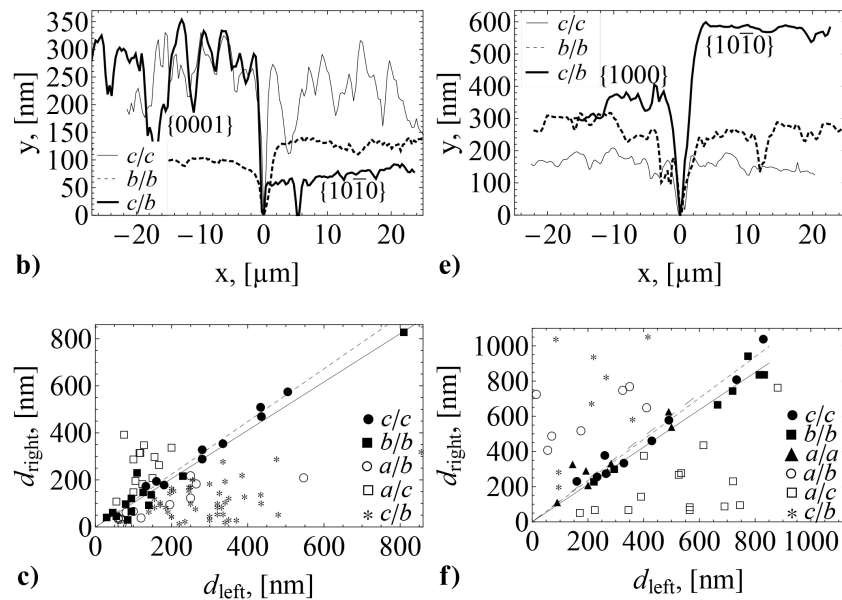

Figure 5. Orientation dependence of height difference between grains after annealing at $392^{\circ} \mathrm{C}$ for $48 \mathrm{~h} \mathrm{(a-c)} \mathrm{and} \mathrm{at} 568^{\circ} \mathrm{C}$ for $4 \mathrm{~h}$ (d-f). (a) and (d) AFM image with (0001) and (1010) surfaces, (b) and (e) profile normal to grain boundary, $x / x$ describes the surface orientation of neighboring grains where $a=(11 \overline{2} 0), b=(10 \overline{1} 0)$, and $c=(0001)$, (c) relation between groove depth of left and right groove sides and orientation. Differences in groove depth, i.e., step height, are most pronounced for neighboring grains with different orientations.

in either temperature, annealing time, or pressure (Fig. 6b, Table 2). Actually, a detailed statistical analysis for experiments run at $392^{\circ} \mathrm{C}$ revealed that dissolution grooves, i.e., without humps, are slightly less deep than grooves with distinct humps, such that the average groove depth is not significantly biased by the relative abundance of measurements for a specific groove morphology.

Annealing time has a profound effect on the statistics of the ratio between step height and groove depth $h / d$ (Fig. 8). Samples from short experiments are dominated by a large step/depth ratio. With increasing annealing time, the number of steps decreases and grooves become relatively deeper compared to step height. Finally, we observe many steps with deep grooves (small $h / d$ ) for samples of the longest experiments. In sequential annealing experiments, grooves deepen systematically, too (Fig. 9). Similarly, the height of the many steps systematically increases with the number of sequences reaching up to $400 \mathrm{~nm}$, a magnitude not observed for single anneals, even after the longest durations.

An increase in temperature by about $100^{\circ} \mathrm{C}$ results in grooves approximately two to three times deeper for fixed 


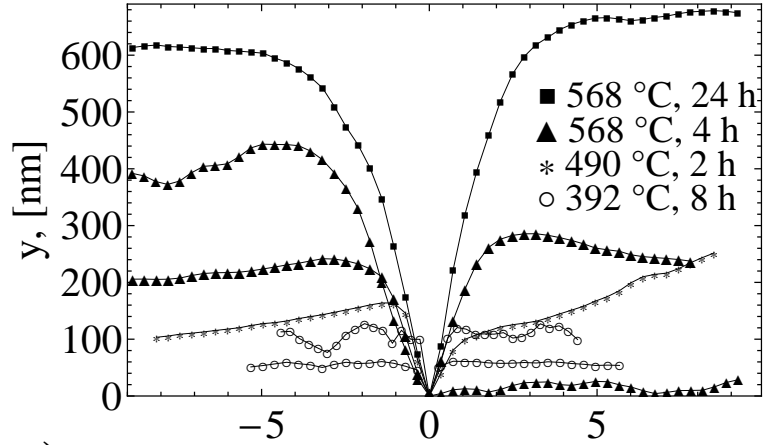

a)

$\mathrm{X},[\mu \mathrm{m}]$

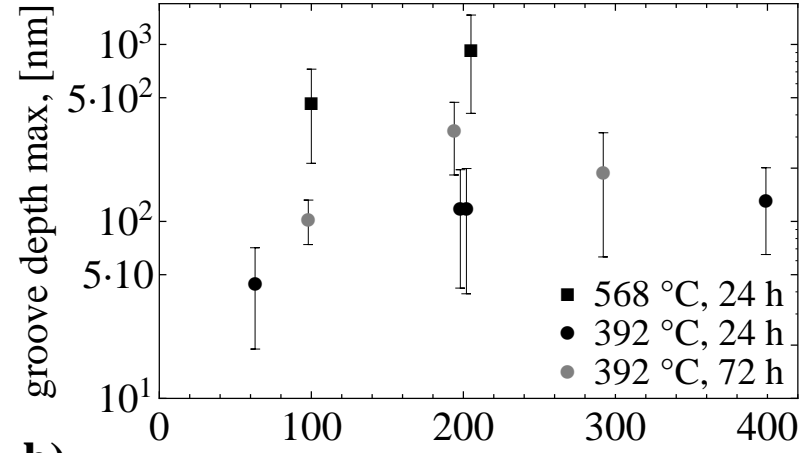

pressure, $[\mathrm{MPa}]$

Figure 6. (a) Examples of observed groove geometries at a pressure $\sim 200 \mathrm{MPa}$. (b) Groove depth, $d_{\text {max }}$ (average and standard deviation, see Table 2), as varying with pressure. Annealing conditions, temperature and duration are indicated by the labels.

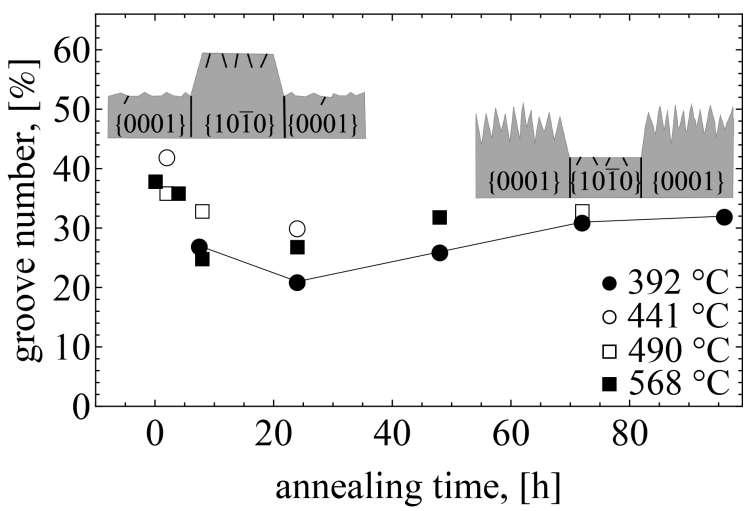

Figure 7. Evolution of the fraction of grooves identified to be due to dissolution. The images show schematic differences in surface geometry for long and short experiments (see also Fig. 4) for which a switch from preferential dissolution of $c=(0001)$ surfaces to preferential growth on these relative to prismatic surfaces $b=(1010)$ is observed.

pressure and duration (compare for example P47 and P12 or P10 and P15, Table 2). The groove growth-enhancing effect of pressure is reflected by average groove depths that approximately double for a doubling in pressure (compare for example P51 and P10 or P50 and P46, Table 2). Adding $\mathrm{SiO}_{2}$ powder to a capsule leads to deeper grooves and larger steps compared to experiments with only water in the capsules (compare for example P36 and P44, Table 2).

Independent of annealing conditions, geometry of many grooves deviates from the relations between depth and width according to Mullins (1960). Groove width is generally too low for the observed depth and a fairly systematic frequency distribution is found for the difference between observed groove geometries and predictions of the Mullins' theory (Fig. 10). The deviation of the ratio between width and depth of individual grooves from the theoretical ratio between 4.73

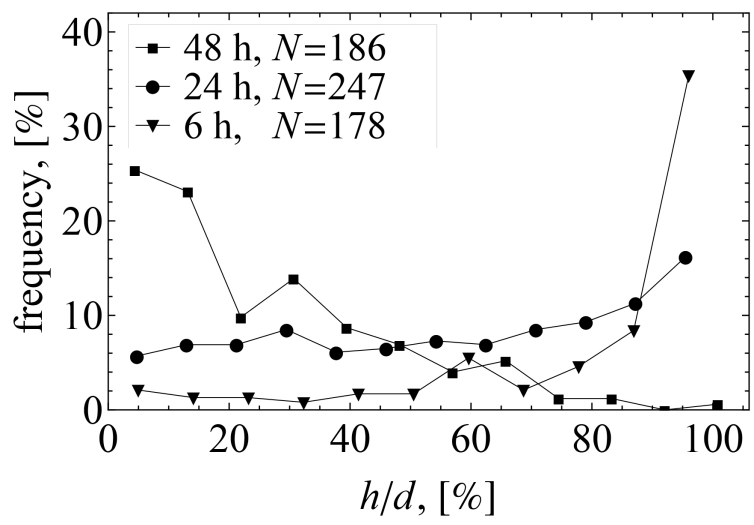

Figure 8. Observed frequency of step height normalized by groove depth after annealing at $392^{\circ} \mathrm{C}$ and $\sim 200 \mathrm{MPa}$ for indicated durations ( $N$ indicates the number of observations).

and 4.95 (see Eqs. 5 and 6) exhibits a maximum from 1 to 2.5 .

\subsubsection{Root angle}

Observed groove-root angles range from 80 to $180^{\circ}$ but angles of about $160^{\circ}$ dominate (Table 2). Within this spread we find some evidence for a systematic relation between root angle and crystallographic orientation of neighboring grains; angles are lowest for intermediate misorientation (Fig. 11a). For a single experiment the frequency distributions of root angles are skewed with a tail to low angles. The reported values for arithmetic mean and standard deviation (Table 2) are not perfectly adequate for a quantity that has a physical upper limit, i.e., $180^{\circ}$, but serve the purpose of indicating the spread.

Mean values of the root angle indicate a tendency for a slight decrease, with increasing annealing temperature and increasing annealing time (Fig. 11b). The effect of experimental duration seems to be confirmed by the sequential 


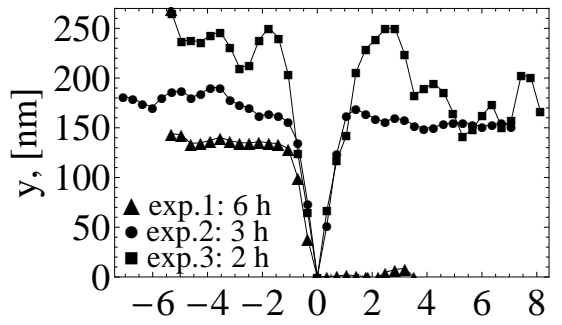

a)

$\mathrm{x},[\mu \mathrm{m}]$

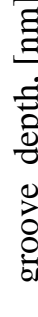

b)

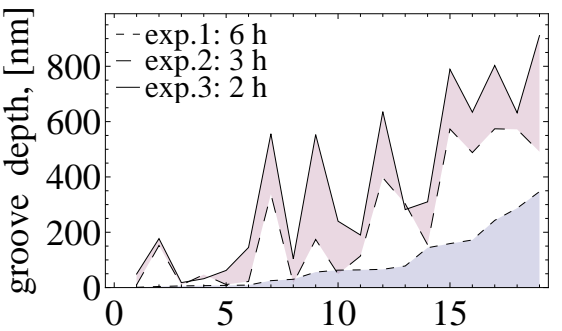

groove number

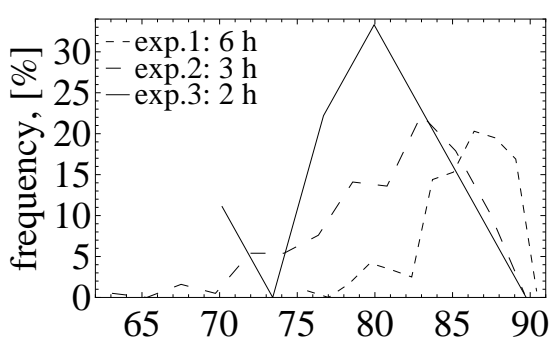

c)

$$
\text { half-root angle } \delta,\left[^{\circ}\right]
$$

Figure 9. Evolution of (a) groove profiles, (b) groove depth and (c) half-root angle $\delta$ in sequential experiments at $392^{\circ} \mathrm{C}$ with a cumulative duration of $11 \mathrm{~h}$ (P40 1-3, see Table 2). In (b) the grooves are ordered by their size after the first annealing step; while most grooves deepen with time the evolution of individual grooves differs considerably. The most frequent half-root angle (c, see also Table 2) decreases with the number of annealing steps. The total number of angles measured is 128, 192, and 12 for the three subsequent experiments.

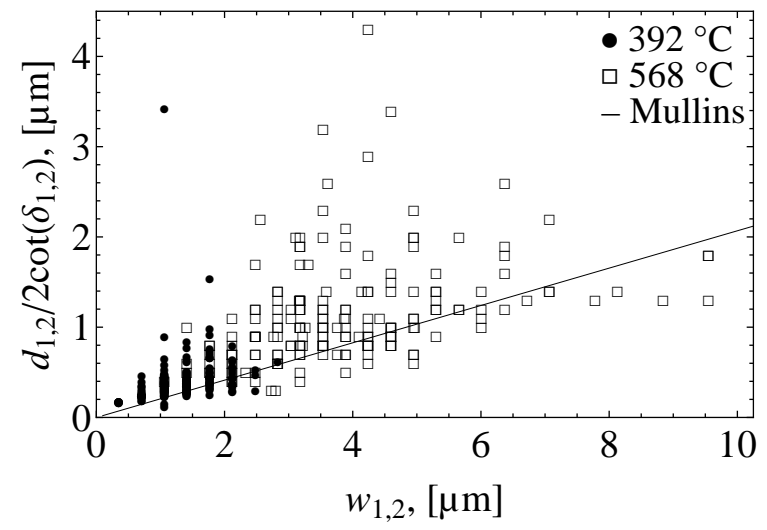

Figure 10. Cross-correlation of weighted groove depth and groove width for annealing at indicated temperatures, $200 \mathrm{MPa}$ and a duration of $24 \mathrm{~h}$. The line represents the expected correlations according to the Mullins' theory (see Eqs. 5 and 6).

annealing experiments (Fig. 9), and becomes more apparent the higher the annealing temperature. Pressure has a subordinate effect (Fig. 11b). At $392{ }^{\circ} \mathrm{C}$ the mean values tend to decrease with increasing pressure (Table 2), but the standard deviations are as large as the possible decrease associated with the pressure range of 63 to $399 \mathrm{MPa}$.

\section{Discussion}

Our experiments are complicated due to the non-equilibrium starting conditions and the likely occurring convection in the capsules. Therefore, it is mandatory to develop a plausible scenario of process sequences from the observations in the light of experimental limitations before actually attempting to constrain the kinetics of individual processes.

\subsection{Experimental limitations}

For our test conditions, we estimate equilibrium concentrations of 0.0294 to $0.1025 \mathrm{~mol}_{\mathrm{SiO}_{2}} \mathrm{~kg}_{\mathrm{H}_{2} \mathrm{O}}{ }^{-1}$ (Table 2) that can be reached by dissolving a layer of 0.3 to $6 \mu \mathrm{m}$ from the entire surface, or a single head face of a cylindrical sample with a diameter of $3 \mathrm{~mm}$, respectively. In the case dissolution were to occur preferentially at grain boundaries by groove etching at a single head face, these concentrations would correspond to an average groove depth of several micrometers for root angles of about $80^{\circ}$, and a polycrystalline aggregate with an average grain size of about $20 \mu \mathrm{m}$. In reality, dissolution simultaneously takes place at grain surfaces and grain boundaries. The early development of steps between neighboring grains indicates preferential dissolution of specifically oriented grain surfaces. Groove depths observed for sequential anneals are significantly larger than for a suite of single anneals (Fig. 12), likely due to repeated dissolution at grain boundaries when a sample is repeatedly heated in the presence of distilled water. Groove depth, however, reaches only tens of nanometers after the shortest annealing durations, in contrast to the estimate of several micrometers if dissolution were to exclusively take place at grain boundaries.

Convection is very likely to occur in our capsules due to thermal gradients. Convection hinders the development of concentration gradients in the fluid that reflect the surface curvature, and thus grooving kinetically controlled by diffusion through the liquid cannot take place. The continuous mixing of the fluid may, however, facilitate dissolutionprecipitation processes associated with local differences in surface energy.

The grain size of the quartzite samples is large enough to avoid overlap of groove profiles from neighboring grain boundaries. Yet, growth and shrinkage of grains may in principle affect root angles (Dillon and Rohrer, 2009). While our samples do not exhibit "abandoned" grooves as evidence for grain boundary migration, the partially blunted roots of grooves may be associated with grain boundary migration (Rabkin et al., 2006) in addition to quenching. 

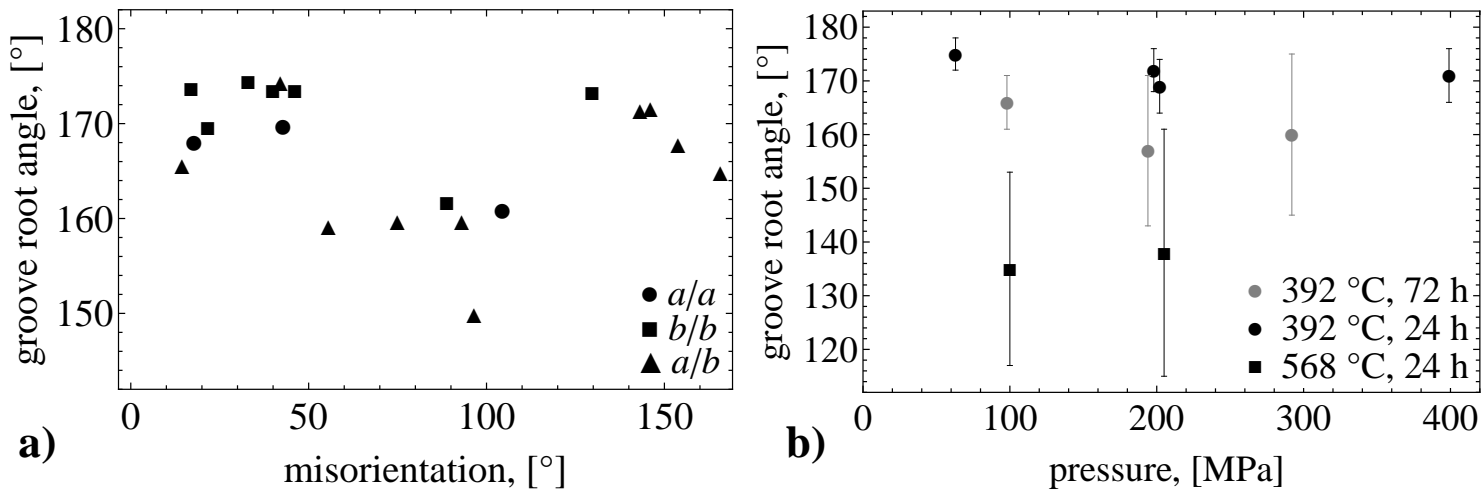

Figure 11. Relation between observed groove-root angle $\alpha$ (see Fig. 1) and (a) misorientation between neighboring grains with $a$ axes or $b$ axes normal to the sample surface and (b) pressure for indicated annealing time and temperature. Misorientation is quantified by the angle between the $c$ axes of the neighboring grains. Error bars represent standard deviations (see Table 2).

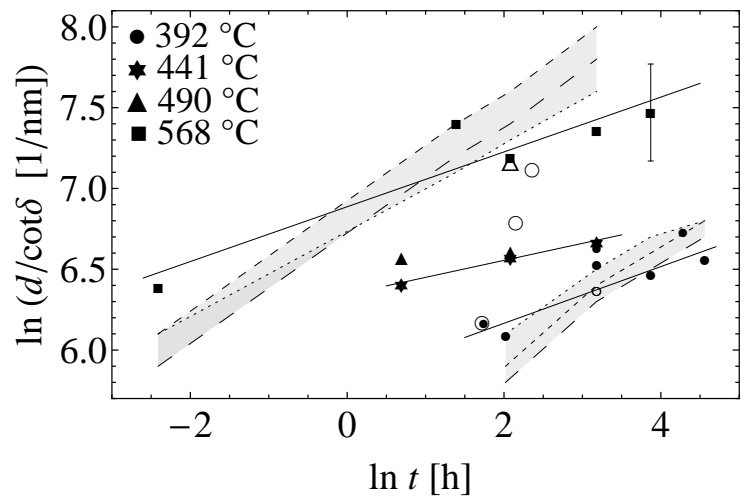

Figure 12. Correlation of the average ratio of groove depth and cotangent of groove-root angle with annealing time for experiments run at indicated temperatures and a pressure of $\sim 200 \mathrm{MPa}$. The standard deviation of the observations is given by vertical error bars for only one representative example out of presentational reasons. Only those grooves were used to determine average groove parameters at given conditions that exhibit a width/depth ratio that does not deviate from the value of the Mullins' theory by more than 0.15 (see Eqs. 3 and 4). The solid lines represent linear regressions for subgroups of the data set (solid circles $392^{\circ} \mathrm{C}$, solid stars $441^{\circ} \mathrm{C}$, and solid squares $568^{\circ} \mathrm{C}$ ). The slope corresponding to the inverse of the growth exponent $n$ is less than that of the dashed lines, representing the results of the inversion for kinetic parameters of the three considered scenarios, interface diffusion (dotted line, $n=4$ ), diffusion through liquid (short dashed, $n=3$ ) and diffusion through the solid (long dashed, $n=3$ ) (see Eq. 4 and Table 3) and thus, at face value, the data yield growth exponents larger than the ones predicted by Mullins' theory. The open triangle represents an experiment with added $\mathrm{SiO}_{2}$ powder. The large open circles indicate the sequential experiment that were not included for the inversion.

\subsection{Process sequence in experiments}

We tentatively distinguish three processes responsible for the observed groove and surface geometries. Initially, dissolution processes are active predominantly during heating, but also slightly beyond until the liquid is saturated in $\mathrm{SiO}_{2}$. Then, dissolution-precipitation processes and grooving occur simultaneously at constant bulk composition of the liquid. The grooving involves diffusion to some extent as evidenced by the humps flanking a fraction of the grooves. Finally, precipitation may occur during the reduction in temperature and pressure when terminating an experiment.

The initial dissolution processes, active until saturation of the liquid is reached, are heterogeneous as documented by the steps exhibiting orientation-dependent heights. At this stage, grains with the $c$ axes perpendicular to their surface seem to be most prone to dissolution. The survival of scratch traces on the high-lying surfaces (inferred to be (1010), Fig. 3a) indicates subordinate dissolution of these surfaces in short experiments.

With respect to scratch occurrence and intensity, the optical observations are consistent with the dependence of step development on temperature and annealing time. The increase in step height with every new heating stage of sequential annealing experiments supports our notion of preferred solution of specific surfaces (Fig. 9). The initial topographic characteristics are affected by polishing treatment and the addition of quartz powder. At a temperature of $568^{\circ} \mathrm{C}$, grooves are deeper when $\mathrm{SiO}_{2}$ powder is added to the charge than when it is not (Table 2). Apparently, a finite amount of the entire surface is dissolved from samples when no powder is added. This bulk dissolution masks the grooving, that is, the grooves do not significantly "outrun" the dissolution front. Yet, when powder is added saturation is likely achieved by preferentially dissolving the powder and grooving is more prominent right from the start. The differences in early groove depth between the two charge types is consistent with the order of magnitude of our estimates on how thick a layer to be removed from samples' surfaces to reach saturation. 
The second stage is characterized by increasing groove depth, an inversion of individual steps, but also by the occurrence of pocks on some surfaces. Furthermore, the number of steps and dissolution grooves tend to decrease at the beginning of this phase (Fig. 7). In contrast to the initial stage, during which massive disequilibrium between the liquid and the solid triggers all possible dissolution processes, now precipitation also takes place, as likely evidenced by the pocks, and balances ongoing dissolution driven by subtle differences in surface energies of different orientations and between intact lattice and defects. Previously preferentially dissolved grains with the $c$ axes normal to their surface (compare Gratz and Bird, 1993a; Gratz et al., 1990) now apparently grow as indicated by the pocks with prismatic habitus (Figs. 3c and 4 right). This switch from preferential dissolution during the equilibration to growth at equilibrium concentration may be related to a contrasting order of dissolution kinetics and surface energy for the low index orientations. Several previous studies found that $c$ faces grow faster than any other face at conditions not too far away from the ones of our experiments (Laudise, 1959; Okamoto and Sekine, 2011; Ostapenko and Mitsyuk, 2006). Surfaces that experienced substantial dissolution may also simply have developed a defect structure that is particularly suitable for subsequent precipitation (compare Bickmore et al., 2008; Schlegel et al., 2002). The precise nature of the temperature and time dependence of these dissolution-precipitation processes remains unclear. Furthermore, the necessary local transport of the solid's constituents between "neighboring" grains may be affected by convection in the capsule.

Finally, the cooling phase should be characterized by precipitation processes since the fluid is oversaturated. We tentatively link at least some of the isolated pocks with this stage (Fig. 3d).

\subsection{Groove-root angles}

Groove-root angles constitute a prominent quantitative measure of groove geometry constraining the ratio of involved interface energies, i.e., dihedral angles, albeit approximately. The comparison between groove angles found in this study and previously reported dihedral angles has to acknowledge that root angle and dihedral angle coincide only for grain boundaries that are perpendicular to the free surface; the larger the boundary tilt, the more groove-root angles fall short of dihedral angles (Hackl et al., 2012), in other words, the groove-root angles measured by us constitute lower bounds for dihedral angles. Additional complexity due to orientation dependence of surface energy is indicated by the observed relations between grain level and orientation as well as between groove-root angle and misorientation of neighboring grains (Fig. 11a), showing some similarity to observations made for ice (Suzuki and Kuroiwa, 1972). Technically, however, our measurements constitute a more direct determination of angles with a higher spatial resolution than the previous studies by Holness $(1992,1993)$ and Laporte and Watson (1991).

Observed groove-root angles are on average up to twice as large as the fairly constant dihedral angles previously reported by Holness (1992) for pressures between 100 and about $600 \mathrm{MPa}$ at a temperature of $800^{\circ} \mathrm{C}$, i.e., higher than the temperatures investigated in this study. Above about $600 \mathrm{MPa}$, a significant decrease in the dihedral angle with increasing pressure was found in that study, in agreement with earlier data from Laporte and Watson (1991). A similar behavior was found for temperatures lower than $800^{\circ} \mathrm{C}$, too (Holness, 1993), suggesting that angles decrease with pressure beyond a "critical" pressure that decreases with temperature. Our observations extend the general decreasing trend with pressure to low pressures. While Holness (1993) found increasing dihedral angles with increasing temperature for $T>450^{\circ} \mathrm{C}$ at a pressure of $400 \mathrm{MPa}$, our observations indicate a modest decrease in root angles with increasing temperature between 392 and $568{ }^{\circ} \mathrm{C}$ and pressures between 100 and $200 \mathrm{MPa}$ (Fig. 11b). Given the complex variation of dihedral angles with temperature and pressure and potential methodological differences, the apparent discrepancies between our estimates and previous measurements may actually be a result of the lack of overlap in conditions.

The observed tendency for slightly decreasing root angles with increasing annealing time (Fig. 9) is the opposite of expectations, due to the difference between the true dihedral angle as an energy ratio and the groove-root angle of tilted boundaries (Hackl et al., 2012) when speculating that grain boundaries tend to re-orient towards a normal intersection with the surface for increasing annealing time, as known from thin films (e.g., Thompson, 1990). This anticipated reorientation should rather yield an increase in the grooveroot angle with time. Alternatively, evolution in grain boundary/surface energy ratio due to segregation impurity, for example, has been invoked as an explanation for the change in the groove-root angle with time (Zhang et al., 2002). Also, the blunting effect of grain-boundary migration on root angles (Dillon and Rohrer, 2009) might contribute to the evolution.

\subsection{Constraints on kinetic parameters}

\subsubsection{Selection criteria and evaluation procedure}

In the quest for kinetic parameters for the surface evolution, one can either analyze the entire profile of individual grooves or rely on the variation of statistical groove characteristics with experimental conditions. The various approximate approaches of Mullins $(1960,1957)$ have the advantage of providing analytical expressions for groove profiles.

Asymmetry is not predicted by any of the Mullins' theories. Grooves exhibit asymmetry with respect to the root due to differences in the height level of neighboring grains, i.e., steps, and due to tilt of the enclosed grain boundary or 
anisotropy of kinetic parameters. For such grooves, extended approaches have to be considered (e.g., Hackl et al., 2012; Rabkin et al., 2001); however, these lack analytic expressions suitable for a fitting exercise. Nonetheless, when the surface evolution does not include transport from one side of the groove to the other, groove halves can be treated separately. Thus, for grooves with steps, a separate treatment of groove halves is appropriate as long as the presence of the steps does not trigger a transport process between the neighboring grains. Yet, transport from one grain to the other will occur when the grain boundary is tilted or kinetic parameters are dependent on orientation.

The performed surface measurements do not allow us to determine tilt of grain boundaries. Initial results of an ongoing numeric study in which we investigate the relation between grain boundary tilt and groove geometry and its evolution for surface diffusion as rate-controlling process suggest that asymmetry remains modest and the temporal evolution of tilted grooves does not deviate strongly from that of straight Mullins' grooves, but for severely tilted grain boundaries for the large dihedral angles characteristic of the $\mathrm{SiO}_{2}-$ $\mathrm{H}_{2} \mathrm{O}$-system (Hackl et al., 2012).

We fit the analytical expressions to the selected observed profiles to constrain kinetic parameters (see examples in Fig. 13). Aiming at an order of magnitude constraint on kinetic parameters, we simplistically treat the two groove flanks independently and prescribe the dihedral angle of the analytical expression by the actual observed angle between groove flank and the normal to the flat surface, i.e., the halfroot angle.

For the derivation of kinetic parameters from the variation of statistical groove characteristics with experimental conditions, we selected a subset of the standard "single-anneal" experiments for which polishing was identical to fit evolution laws to averaged groove depth and (half-)width. The two groove sides are again treated separately and among the many investigated grooves we used only those whose depth/width ratio agrees with the average of 4.84 of the theoretical Mullins' values (4.73 and 4.95, see Eqs. 2 and 3) within \pm 0.15 . As noted above, groove widths are generally too low in comparison to observed depths, in other words, many grooves exhibit depth/width ratios $<4.73$ (Fig. 10). Grain boundary sliding due to assimilation of dislocations tends to reduce the width of grooves compared to the Mullins' theory (Rabkin et al., 2001), yet this mechanism likely plays no role in our experiments given the low homologous temperatures. Sequential annealing experiments were not considered for the fitting exercise because of the obvious bias of groove geometry due to the repeated dissolution during equilibration of capsules. Despite the variability of groove characteristics in a single experiment, this subset of observations represents thermally activated groove growth (Fig. 10). At face value, the measured data follow relatively large growth exponents in comparison to the theoretical values of 3 or 4 (Fig. 12).
Kinetic parameters quoted in Table 3 (pre-factor $D_{0}$, apparent activation enthalpy, and apparent activation volume) were deduced by non-linear inversion (Sotin and Poirier, 1984) employing Eqs. (3) and (4) for the three alternative diffusion paths (through the liquid, along the solid-liquid interface, through the solid) and fixing the growth exponent $n$ accordingly. The quoted ranges in the kinetic parameters reflect the experimental uncertainties. For the inversion, every experiment is characterized by a set of values for groove depth, groove width, groove-root angle, temperature, time, and pressure and we use the standard deviation as a measure of uncertainty for the geometrical groove parameters while pressure, temperature and time are assigned accuracies of $20 \mathrm{MPa}, 10^{\circ} \mathrm{C}$, and $5 \mathrm{~min}$, respectively. We use statistical parameters for the uncertainties in groove depth and width rather than uncertainties in the measurements for individual grooves' attempts to address the possible variability in genesis. Molecular volume, grain boundary width, surface energy, thickness of the layer in which surface diffusion takes place, and equilibrium concentration of solute in the solvent are assumed known parameters for the inversion (see Table 1). Consideration of their uncertainties does not add significantly to the uncertainty of derived kinetic parameters in light of the considered uncertainties of groove parameters and experimental conditions. Isotropy of interface energy and diffusion coefficients is an assumption inherent to the theoretical treatment that is probably not fully justified for a low-symmetry mineral such as low quartz.

\subsubsection{Results and their comparison to previous studies}

A large number of grooves resemble and are actually fit by the dissolution geometry. Individual grooves however exhibit better resemblance to one of the two others of the three potential analytical profiles (dissolution, surface diffusion, diffusion through liquid; Fig. 13). From these, kinetic parameters were determined for the two alternative processes, surface diffusion and diffusion through the liquid (Fig. 12). The resulting diffusion coefficients range from $10^{-11}$ to $10^{-13} \mathrm{~m}^{2} \mathrm{~s}^{-1}$.

Order of magnitude-wise, the diffusion coefficients inverted from the selected subset of groove-depth and groovewidth observations are similar to the ones derived from the analysis of individual groove profiles. The constrained kinetics from either approach is several orders of magnitude too large in comparison to literature values for Si-diffusion in quartz yet too small in comparison to estimates for the diffusion coefficient of $\mathrm{Si}$ through $\mathrm{H}_{2} \mathrm{O}$ (Fig. 14). Our calculations for the case of diffusion preferentially along solid-liquid interfaces are fairly close to previously reported results for $\mathrm{Si}$ diffusion along wet grain boundaries or interface diffusion.

The activation energies found from the various models range from 88 to $159 \mathrm{~kJ} \mathrm{~mol}^{-1}$ (Table 3).

Specifically, for interface diffusion we estimate an activation energy of $132 \pm 25 \mathrm{~kJ} \mathrm{~mol}^{-1}$ in close agreement with 
Table 3. Results from fit of growth law (3) to observations of $d / \cot \delta$, employing the explicit formulations given in Table 1.

\begin{tabular}{lccc}
\hline Diffusion path & $\begin{array}{c}\text { Pre-factor } D_{0, i} \\
\left(\mathrm{~m}^{2} \mathrm{~s}^{-1}\right)\end{array}$ & $\begin{array}{c}\text { Activation energy } E_{i} \\
\left(\mathrm{~kJ} \mathrm{~mol}^{-1}\right)\end{array}$ & $\begin{array}{c}\text { Activation volume } V_{i} \\
\left(\mathrm{~cm}^{3} \mathrm{~mol}^{-1}\right)\end{array}$ \\
\hline Through crystal $(i=\mathrm{v})$ & $3 \times 10^{-12 \pm 2}$ & $113 \pm 24$ & $-104 \pm 37$ \\
Through fluid volume $(i=1)$ & $3 \times 10^{-9 \pm 2}$ & $115 \pm 23$ & $-98 \pm 37$ \\
Surface diffusion $(i=\mathrm{s})$ & $4 \times 10^{-8 \pm 2}$ & $133 \pm 25$ & $-105 \pm 37$ \\
\hline
\end{tabular}

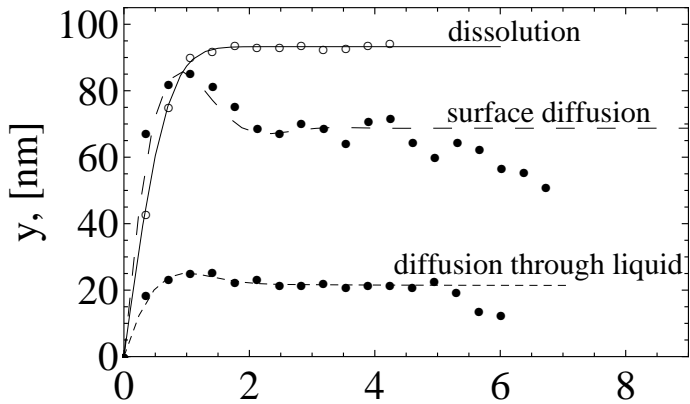

a) $\mathrm{x},[\mu \mathrm{m}]$

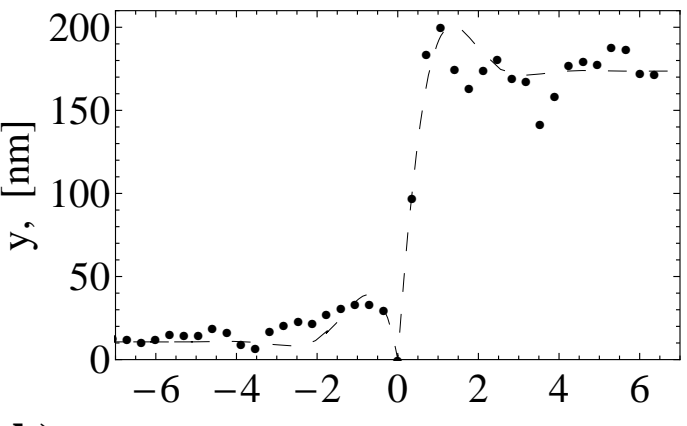

b)

$\mathrm{x},[\mu \mathrm{m}]$

Figure 13. Fit of theoretical groove shape (according to Mullins' theory) to individual groove profiles (points) observed for annealing experiments at (a) $392^{\circ} \mathrm{C}$ and $7.5 \mathrm{~h}$ and (b) $392^{\circ} \mathrm{C}$ and $48 \mathrm{~h}\left(D_{\mathrm{s}}=1.6 \times 10^{-14} \mathrm{~m}^{2} \mathrm{~s}^{-1}, \delta=83.7^{\circ}\right)$. The line styles of the fitted model curves in (a) are chosen such that solid, long-dashed or short-dashed lines correspond to grooving kinetically controlled by dissolution $\left(\mathrm{m}\left[\mathrm{SiO}_{2}\right]=4 \times 10^{-10} \mathrm{~mol} \mathrm{~kg}-1, \delta=83^{\circ}\right)$, by surface diffusion $\left(D_{\mathrm{s}}=3.6 \times 10^{-14} \mathrm{~m}^{2} \mathrm{~s}^{-1}, \delta=77^{\circ}\right)$ or by diffusion through liquid $\left(D_{1}=\right.$ $\left.9.5 \times 10^{-14} \mathrm{~m}^{2} \mathrm{~s}^{-1}, \delta=86.5^{\circ}\right)$, respectively.

the activation energy of $137 \pm 18 \mathrm{~kJ} \mathrm{~mol}^{-1}$ for diffusion of $\mathrm{Si}$ - the slower of the two components $\mathrm{Si}$ and $\mathrm{H}$ (Farver and Yund, 1991) - along wet grain boundaries (Farver and Yund, 2000). The activation energy here deduced for grooving dominated by diffusion through the liquid $\left(115 \pm 23 \mathrm{~kJ} \mathrm{~mol}^{-1}\right)$ largely exceeds the currently available constraints on the activation energy for Si diffusion through water for which Watson and Wark (1997) estimate about $21 \mathrm{~kJ} \mathrm{~mol}^{-1}$ from an evaluation of the Stoke-Einstein relation between diffusion coefficient and viscosity, while their experimental data yield $52 \pm 9 \mathrm{~kJ} \mathrm{~mol}^{-1}$ at temperatures of $530^{\circ} \mathrm{C}$ to $800^{\circ} \mathrm{C}$ and a pressure of $1 \mathrm{GPa}$. A single observation at $0.6 \mathrm{GPa}$ indicates a subordinate effect of pressure.

For the most part, the range of activation energies found here further exceeds previously reported values for the activation energy of dissolution, $89 \pm 5 \mathrm{~kJ} \mathrm{~mol}^{-1}$ (Tester et al., 1994), $71 \pm 9 \mathrm{~kJ} \mathrm{~mol}^{-1}$ (Dove and Crerar, 1990), and 67 to $77 \mathrm{~kJ} \mathrm{~mol}^{-1}$ (Rimstidt and Barnes, 1980), and precipitation/growth, $84 \pm$ (4-8) $\mathrm{kJ} \mathrm{mol}^{-1}$ (Laudise, 1959; Ostapenko and Mitsyuk, 2006). These rather low values likely document that dissolution of real crystals is dominated by processes at crystal defects (see discussion by Adeagbo et al., 2008; Dove and Crerar, 1990). By ab initio molecular dynamics simulations, Adeagbo et al. (2008) found a barrier for the dissolution of $\mathrm{SiO}_{2}$ from a perfect, defect-free crystal surface of about $186 \mathrm{~kJ} \mathrm{~mol}^{-1}$, representing breakage of the first $\mathrm{Si}-\mathrm{O}$ bond in fair agreement with the prediction of $228 \mathrm{~kJ} \mathrm{~mol}^{-1}$ for breaking $\mathrm{Si}-\mathrm{O}$ bonds, gained by dividing the heat of formation of $\mathrm{SiO}_{2}$ by the coordination of $\mathrm{Si}$. Probably constituting the opposite extreme of a perfect crystal, modeling of the hydroxylation of $\mathrm{Si}(\mathrm{OH})_{4}$ in the gas phase by Lasaga and Gibbs (1990) yield a lower activation energy ranging between 64 and $120 \mathrm{~kJ} \mathrm{~mol}^{-1}$ more closely agreeing with the experimentally derived values.

The apparent activation volumes gained for the various models all range at about $-100 \mathrm{~cm}^{3} \mathrm{~mol}^{-1}$ (Table 3), i.e., about four times the molecular volume of quartz, indicating that the activation of large molecule complexes is involved in the surface evolution (compare the suggestion by Gerya et al. (2004) that $\alpha$-quartz has to be treated with a stoichiometry of $\mathrm{Si}_{3} \mathrm{O}_{6}$ when modeling the $\alpha-\beta$ transition of quartz).

The compilation of available diffusion coefficients in the system $\mathrm{SiO}_{2}-\mathrm{H}_{2} \mathrm{O}$ (Fig. 14) strongly suggests that $\mathrm{Si}$ transport through the fluid should be the fastest path for the slowest constituent and thus rate-limiting if grooving were controlled by diffusion. However, the current constraints on the kinetics of Si-diffusion through $\mathrm{H}_{2} \mathrm{O}$ (Adeagbo et al., 2008; Doltsinis et al., 2007a) suggest much faster groove growth for the conditions of our experiments than we actually observed. Furthermore, the observed strong effect of pressure on grooving is at odds with an inference from Watson and Wark (1997) that Si-diffusion through water is insensitive to pressure further supporting the interpretation that diffusion 
through the liquid is not the rate-controlling process in our experiments.

In principle, any step in the chain dissolution-transportprecipitation could be rate limiting. A control by interface reaction kinetics, either of the dissolution or the precipitation step, cannot be excluded per se. In our experiments, Si-concentration gradients in the liquid above the solidliquid interface are likely continuously disturbed by convection. Continuous advection of dissolved atoms may therefore cause some deepening of grooves to be controlled by dissolution driven by local differences in solubility. The numerical coincidence of the apparent activation energies derived from dissolution-precipitation creep experiments on quartz aggregates under hydrous conditions, and that of dissolution kinetics, was considered evidence for dissolution as controlling the rates of this "deformation by mass transfer" (Dewers and Hajash, 1995; Gratier and Guiget, 1986; Niemeijer et al., 2002; Schutjens, 1991). The discussions presented in the deformation studies excluded diffusion through the liquid, the only considered alternative, due to the large deviation between activation energies of dissolution kinetics (about $\left.80 \mathrm{~kJ} \mathrm{~mol}^{-1}\right)$ and diffusion in the liquid (10 to $\left.20 \mathrm{~kJ} \mathrm{~mol}^{-1}\right)$. Yet, alternatively a diffusion process that does not require a dissolution step may be rate-controlling, i.e., interface diffusion or lattice diffusion. Of these two diffusion paths, interface diffusion appears much more likely given the constraints on lattice diffusion kinetics, and in fact our estimates for interface diffusion coefficients are fairly compatible with previously reported values (Fig. 14). In conclusion, groove geometry (presence/absence of humps) as well as characteristics of groove development (activation energy) indicate that a diffusion process is involved that leads to grooving rates at least comparable to the surface alterations associated with coeval dissolution processes.

\subsection{Implications}

Obviously, the system $\mathrm{SiO}_{2}-\mathrm{H}_{2} \mathrm{O}$ is at best a gross simplification of the complex mineralogy and chemical composition of rocks and fluids in the continental crust. Dissolution (see for example Dove et al., 2005; Newton and Manning, 2010; Xie and Walther, 1993) and likely precipitation of quartz (and more complex silicates) depends on fluid composition. Little can be said about the effect of fluid composition on interface diffusion. The agreement between the activation energies for interface diffusion in contrasting environments (wet grain boundaries vs. wollastonite rims, see Fig. 14) indicates a subordinate effect. Thus, we consider the gained constraints on transport kinetics in the system $\mathrm{SiO}_{2}-\mathrm{H}_{2} \mathrm{O}$ at conditions representing a depth of 10 to $20 \mathrm{~km}$ in the continental crust as suitable for a tentative zero-order analysis of the characteristics of microstructural alterations, such as crack healing in hydrothermal environments, and associated recovery (e.g., Tenthorey et al., 2003).

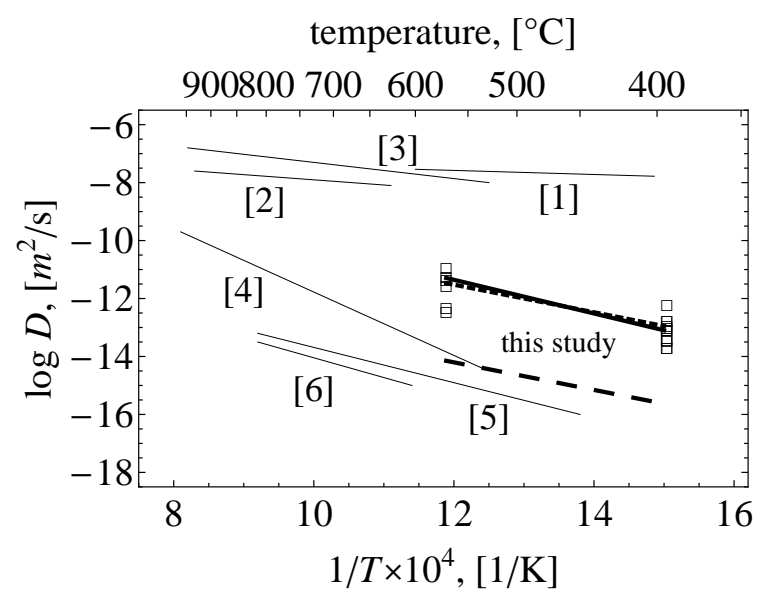

Figure 14. Diffusion coefficients constrained by the analyses performed in this study in comparison to previously reported values. Open squares represent the results from fitting individual grooves with the analytical groove shapes suggested by the Mullins' theory (see also Fig. 12). The thick lines labeled "this study" represent the results from fitting sets of groove characteristics (see also Fig. 13, Eqs. 3 and 4 with kinetics data from Table 3; solid line: surface diffusion through fluid volume; dotted line: diffusion through fluid volume; dashed line: diffusion through crystal). Thin solid lines refer to literature values: [1] Stokes-Einstein relation for $1 \mathrm{GPa}$ (Watson and Wark, 1997); [2] $\mathrm{SiO}_{2}$ diffusivity at $1 \mathrm{GPa}$ (Watson and Wark, 1997); [3] diffusion of $\mathrm{Si}(\mathrm{OH})_{4}$ in bulk water at $900{ }^{\circ} \mathrm{C}$, $500 \mathrm{MPa}$ (Doltsinis et al., 2007a); [4] grain boundary diffusion of $\mathrm{SiO}_{2}$ constrained by growth rates of wollastonite rims observed in contact metamorphic rocks (Joesten and Fisher, 1988); [5] hydrothermal grain boundary diffusion of O (Farver and Yund, 1991); [6] hydrothermal grain boundary diffusion of Si for 600 to $800^{\circ} \mathrm{C}$, $150 \mathrm{MPa}$ (Farver and Yund, 2000).

From a micromechanical perspective, healing and sealing of cracks involves a sequence of modifications first of planar then of cylindrical void surfaces, and it has been suggested that the ovulation of cylindrical pores due to the RayleighTaylor instability (Nichols, 1976) is rate-controlling in this complex process (e.g., Smith and Evans, 1984). The ovulation in turn is controlled by the same kinetic parameters as hydrothermal grooving. Therefore, we use the derived constraints on kinetic parameters to estimate the characteristic time of ovulation. This estimate constitutes an upper bound for the "real" time since - as explained above - the derived kinetic parameters represent situations involving nonstagnant fluids. When fluids were at rest in the cracks, healing could potentially proceed much faster by diffusion of $\mathrm{Si}$ through the liquid. The activation energy for crack healing of $80 \pm 26 \mathrm{~kJ} \mathrm{~mol}^{-1}$ experimentally determined at conditions comparable to ours (Brantley et al., 1990) overlaps with our estimated activation energy for interface diffusion (Table 3 ). 


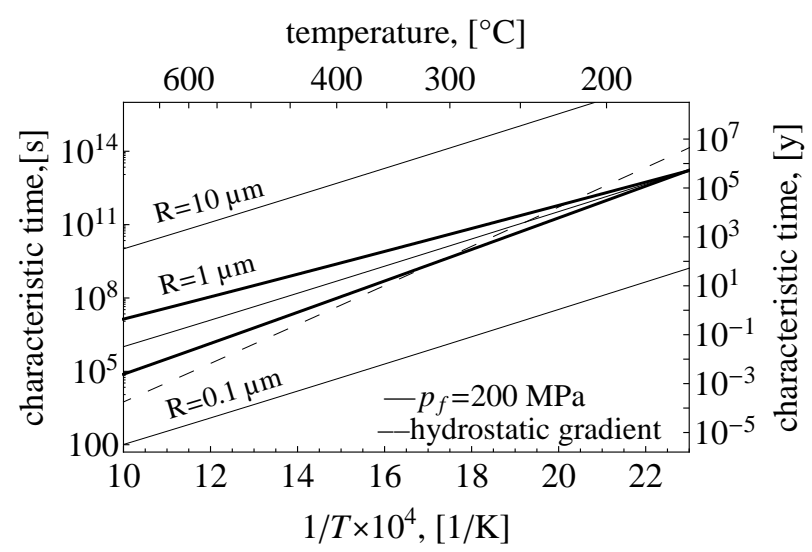

Figure 15. Prediction of characteristic time for crack healing according to Eq. (8) using the constraints on kinetic parameters for surface diffusion as rate-controlling mechanism (Table 3). Crack widths, i.e., radius of the ovulating cylinder, of $0.1,1$, and $10 \mu \mathrm{m}$ were considered in the calculations. Calculations were performed for a constant fluid pressure (solid lines) and a fluid pressuretemperature relation according to a geotherm of $30 \mathrm{~K} \mathrm{~km}^{-1}$ and a hydrostatic pressure gradient. The thick solid lines explicitly indicate the uncertainty in the prediction for a constant fluid pressure and a crack width of $1 \mu \mathrm{m}$, resulting from the quoted uncertainty in kinetic parameters. A similar range is produced for the model with fluid pressure following a hydrostatic gradient.

For a cylinder of radius $R$, the characteristic time $\tau$ for the first ovulation is given by

$\tau \simeq 6.6 \frac{R^{4}}{B_{\mathrm{S}}}$,

when the cylinder geometry exceeds a critical aspect ratio and surface alteration is kinetically controlled by surface (interface) diffusion with the kinetic parameters $B_{\mathrm{S}}$ as defined in Table 1. Relying on Eq. (8) and our constraints on kinetic parameters (Table 3), predicted characteristic times range from weeks to centuries, depending on temperature and pressure (Fig. 15). One class of models for occurrence and recurrence of mid-crustal earthquakes (e.g., Gratier et al., 2002) rests on "cyclic" variations in effective stresses due to dilation and permeability increase associated with crack generation, subsequent healing and permeability reduction (e.g., Brantley et al., 1990; Morrow et al., 2001). In this context, our estimate for healing times should be comparable to the order of magnitude of recurrence intervals and the times over which substantial healing occurs as deduced from geophysical surveys (e.g., Li et al., 1998, 2006; Peng and Ben-Zion, 2006). The range of characteristic healing times deduced from this study (Fig. 15) seems fairly comparable to, if not somewhat larger than, the typical range of recurrence intervals of about 1 to 1000 years and the time span of months to years for which healing is deduced from field surveys. An overestimation is notably consistent with the expectation that the transport kinetics for non-stagnant fluids derived here yield upper bounds for characteristic times of healing. The order of magnitude consistency between our predictions and observations should be taken as motivation for more detailed studies since clearly a number of factors - not accounted for here - may affect healing, such as differences between fluid pressure and total pressure or directed loading and mineralogical variability.

\section{Conclusions}

We experimentally explored the potential of investigating surface grooving of quartzite samples in a hydrothermal environment for providing constraints on transport paths and associated kinetic parameters of processes controlling the evolution of the solid's surface. In principle, analyses of grooves bear a great potential for constraining needed kinetic parameters, yet, several complications are encountered in this approach. Disequilibrium in the capsule requires dissolution until saturation, causing surface alterations and masking the early stages of grooving. Dissolution-precipitation processes due to local differences in solubility prevail after saturation of the fluid and convection takes place continuously at experimentally realizable thermal gradients. Quartz, with its low symmetry, exhibits considerable orientation dependence in surface energy, dissolution-precipitation kinetics, and likely also in surface diffusion coefficients. Potentially, sequential experiments on bi-crystals with specific orientations may help to reach firmer specific conclusions than in our approach employing polycrystalline aggregates. Nevertheless, bulk kinetic parameters were constrained that likely quantify surface diffusion of $\mathrm{Si}$ at hydrothermal conditions. Results of micromechanical modeling of microcrack healing using the derived kinetic parameters compare reasonably well with evidence for postseismic healing from geophysical surveys and recurrence intervals of mid-crustal earthquakes.

Acknowledgements. We gratefully acknowledge funding by the German science foundation. W. Maresch and S. Chakraborty generously permitted usage of the hydrothermal vessel operated by the petrology group at RUB. Sincere thanks go to J. ter Heege for unselfishly sharing characterization information on the used novaculite, R. Neuser for his support during SEM work, F. Bettenstedt for excellently preparing the samples and maintaining the test equipment. We are grateful for meticulous and considerate reviews by A. Gysi and T. Gerya.

Edited by: D. R. Gröcke

\section{References}

Adeagbo, W. A., Doltsinis, N. L., Klevakina, K., and Renner, J.: Transport processes at $\alpha$-quartz-water interfaces: Insights from first-principles molecular dynamics simulations, Chem. Phys. Chem., 9, 994-1002, 2008. 
Bailey, G. L. J. and Watkins, H. C.: Surface tensions in the system solid copper-molten lead, Proc. Phys. Soc. B, 63, 350, 1950.

Bickmore, B. R., Wheeler, J. C., Bates, B., Nagy, K. L., and Eggett, D. L.: Reaction pathways for quartz dissolution determined by statistical and graphical analysis of macroscopic experimental data, Geochim. Cosmochim. Ac., 72, 4521-4536, 2008.

Bokstein, B. S., Klinger, L. M., and Apikhtina, I. V.: Liquid grooving at grain boundaries, Mater. Sci. Eng. A, 203, 373-376, 1995.

Brantley, S. L., Evans, B., Hickman, S. H., and Crerar, D. A.: Healing of microcracks in quartz - implications for fluid flow, Geology, 18, 136-139, 1990.

Dewers, T. and Hajash, A.: Rate equations for water-assisted compaction and stress induced water-rock interaction in sandstones, J. Geophys. Res., 100, 13093-13112, 1995.

Dhalenne, G., Revcolevschi, A., and Monty, C.: Grain boundaries in NiO. II. Determination of mass transport mechanisms by thermal grooving, Physica status solidi (a), 56, 623-636, 1979.

Dillon, S. J. and Rohrer, G. S.: Mechanism for the development of anisotropic grain boundary character distributions during normal grain growth, Acta Mater., 57, 1-7, 2009.

Doltsinis, N. L., Burchard, M., Maresch, W. V., Boese, A. D., and Fockenberg, T.: Ab initio molecular dynamics study of dissolved $\mathrm{SiO}_{2}$ in supercritical water, J. Theor. Comput. Chem., 6, 49-62, 2007a.

Doltsinis, N. L., Maresch, W. V., Burchard, M., and Fockenberg, F.: Dissolved quartz in supercritical water: Insights from ab initio molecular dynamics simulations, Goldschmidt 2007 Cologne, A230-A230, 2007b.

Dove, P. M. and Crerar, D. A.: Kinetics of quartz dissolution in electrolyte solutions using a hydrothermal mixed flow reactor, Geochim. Cosmochim. Ac., 54, 955-969, 1990.

Dove, P. M., Han, N., and De Yoreo, J. J.: Mechanisms of classical crystal growth theory explain quartz and silicate dissolution behavior, P. Natl. Acad. Sci. USA, 102, 15357-15362, 2005.

Farver, J. R. and Yund, R. A.: Oxygen diffusion in quartz - dependence on temperature and water fugacity, Chem. Geol., 90, 55-70, 1991.

Farver, J. R. and Yund, R. A.: Grain-boundary diffusion of oxygen, potassium and calcium in natural and hot-pressed feldspar aggregates, Contrib. Mineral. Petrol., 118, 340-355, 1995.

Farver, J. and Yund, R.: Silicon diffusion in a natural quartz aggregate: constraints on solution-transfer diffusion creep, Tectonophysics, 325, 193-205, 2000

Fournier, R. O. and Potter, R. W.: An equation correlating the solubility of quartz in water from 25 to $900{ }^{\circ} \mathrm{C}$ at pressures up to 10,000 bars, Geochim. Cosmochim. Ac., 46, 1969-1973, 1982.

Fyfe, W. S. and McKay, D. S.: Hydroxyl ion catalysis of crystallization of amorphous silica at 330 degrees $\mathrm{C}$ and some observations on hydrolysis of albite solutions, Am. Mineral., 47, 83-89, 1962.

Gerya, T. V., Podlesskii, K. K., Perchuk, L. L., and Maresch, W. V.: Semi-empirical Gibbs free energy formulations for minerals and fluids, Phys. Chem. Miner., 31, 429-455, 2004.

Gerya, T. V., Maresch, W. V., Burchard, M., Zakhartchouk, V., Doltsinis, N. L., and Fockenberg, T.: Thermodynamic modeling of solubility and speciation of silica in $\mathrm{H}_{2} \mathrm{O}-\mathrm{SiO}_{2}$ fluid up to 1300 degrees $\mathrm{C}$ and $20 \mathrm{kbar}$ based on the chain reaction formalism, Eur. J. Mineral., 17, 269-283, 2005.
Gratier, J. P. and Guiget, R.: Experimental pressure solution deposition on quartz grains: the crucial effect of the nature of the fluid, J. Struct. Geol., 8, 845-856, 1986.

Gratier, J.-P., Favreau, P., Renard, F., and Pili, E.: Fluid pressure evolution during the earthquake cycle controlled by fluid flow and pressure solution crack sealing, Earth Planets Space, 54, 1139-1146, 2002.

Gratz, A. J. and Bird, P.: Quartz dissolution: Negative crystal experiments and a rate law, Geochim. Cosmochim. Ac., 57, 965-976, 1993a.

Gratz, A. J. and Bird, P.: Quartz dissolution: Theory of rough and smooth surfaces, Geochim. Cosmochim. Ac., 57, 977-989, 1993 b.

Gratz, A. J., Bird, P., and Quiro, G. B.: Dissolution of quartz in aqueous basic solution, $106-236^{\circ} \mathrm{C}$ : Surface kinetics of "perfect" crystallographic faces, Geochim. Cosmochim. Ac., 54, 2911-2922, 1990.

Hackl, K., Fischer, F. D., Klevakina, K., Renner, J., and Svoboda, J.: A variational approach to grooving and wetting, Acta Mater. 61, 1581-1591, doi:10.1016/j.actamat.2012.11.035, 2012.

Hay, R. S. and Evans, J. B.: Grain boundary grooving of calcite bicrystals Proceedings of the 24th U.S. symposium on rock mechanics, theory, experiment, practice, American Rock Mechanics Association, Texas, 24, 469-472, 1983.

Herring, C.: Some theorems on the free energies of crystal surfaces, Phys. Rev., 82, 87-93, 1951.

Hilgers, C. and Urai, J. L.: Microstructural observations on natural syntectonic fibrous veins: implications for the growth process, Tectonophysics, 352, 257-274, 2002.

Holness, M. B.: Equilibrium dihedral angles in the system quartz$\mathrm{CO}_{2}-\mathrm{H}_{2} \mathrm{O}-\mathrm{NaCl}$ at $800^{\circ} \mathrm{C}$ and $1-15 \mathrm{kbar}$ : the effects of pressure and fluid composition on the permeability of quartzites, Earth Planet. Sc. Lett., 114, 171-184, 1992.

Holness, M. B.: Temperature and pressure dependence of quartzaqueous fluid dihedral angles: the control of adsorbed $\mathrm{H}_{2} \mathrm{O}$ on the permeability of quartzites, Earth Planet. Sc. Lett., 117, 363377, 1993.

Joesten, R. and Fisher, G. W.: Kinetics of diffusion controlled mineral growth in the Christmas Mountains (Texas) contact aureole, Geol. Soc. Am. Bull., 100, 714-732, 1988.

Keller, W. D., Viele, G. W., and Johnson, C. H.: Texture of Arkansas Novaculite indicates thermally induced metamorphism, J. Sediment. Res., 47, 834-843, 1977.

Klinger, L.: Grain boundary grooving in two component system, Acta Mater., 50, 3358-3395, 2002.

Laporte, D. and Watson, E. B.: Direct observation of nearequilibrium pore geometry in synthetic crustal lithologies, J. Geol., 99, 873-878, 1991.

Lasaga, A. C. and Blum, A. E.: Surface chemistry, etch pits and mineral-water reactions, Geochim. Cosmochim. Ac., 50, 2363 2379, 1986.

Lasaga, A. C. and Gibbs, G. V.: Ab-initio quantum mechanical calculations of water-rock interactions: Adsorption and hydrolysis reactions, Am. J. Sci., 290, 263-295, 1990.

Laudise, R. A.: Kinetics of hydrothermal quartz crystallization, J. Am. Chem. Soc., 81, 562-566, 1959.

Li, Y.-G., Vidale, J. E., Aki, K., Xu, F., and Burdette, T.: Evidence of Shallow Fault Zone Strengthening After the 1992 M7.5 Landers, California, Earthquake, Science, 279, 217-219, 1998. 
Li, Y. G., Chen, P., Cochran, E. S., Vidale, J. E., and Burdette, T.: Seismic evidence for rock damage and healing on the San Andreas Fault associated with the 2004 M 6.0 Parkfield Earthquake, B. Seismol. Soc. Am., 96, S349-S363, 2006.

Manning, C. E.: The solubility of quartz in $\mathrm{H}_{2} \mathrm{O}$ in the lower crust and upper-mantle, Geochim. Cosmochim. Ac., 58, 4831-4839, 1994.

Milke, R. and Heinrich, W.: Diffusion-controlled growth of wollastonite rims between quartz and calcite: comparison between nature and experiment, J. Metamorph. Geol., 20, 467-480, 2002.

Min, D. and Wong, H.: Grain-boundary grooving by surface diffusion with asymmetric and strongly anisotropic surface energies, J. Appl. Phys., 99, 023515, doi:10.1063/1.2159082, 2006.

Morey, G. W., Fournier, R. O., and Rowe, J. J.: The solubility of quartz in water in the temperature interval from 25-degrees to 300-degrees-C, Geochim. Cosmochim. Ac., 26, 1029-1043, 1962.

Morrow, C. A., Moore, D. E., and Lockner, D. A.: Permeability reduction in granite under hydrothermal conditions, J. Geophys. Res., 106, 30551-30560, 2001.

Mullins, W. W.: Theory of thermal grooving, Appl. Phys., 28, 333339, 1957.

Mullins, W. W.: Grain boundary grooving by volume diffusion, Trans. Metall. Soc., 218, 354-631, 1960.

Mullins, W. W. and Shewmon, P. G.: The kinetics of grain boundary grooving in copper, Acta Metall. Mater., 7, 163-170, 1959.

Newton, R. C. and Manning, C. E.: Role of saline fluids in deepcrustal and upper-mantle metasomatism: insights from experimental studies, Geofluids, 10, 58-72, 2010.

Nichols, F. A.: On the spheroidization of rod-shaped particles of finite length, J. Mater. Sci., 11, 1077-1082, 1976.

Niemeijer, A. R., Spiers, C. J., and Bos, B.: Compaction creep of quartz sand at $400-600^{\circ} \mathrm{C}$ : experimental evidence for dissolution-controlled pressure solution, Earth Planet. Sc. Lett., 195, 261-275, 2002.

Okamoto, A. and Sekine, K.: Textures of syntaxial quartz veins synthesized by hydrothermal experiments, J. Struct. Geol., 33, 1764-1775, 2011.

Ostapenko, G. T. and Mitsyuk, B. M.: Growth rate of the $\{0001\}$ and $\{0111\}$ faces of quartz as a function of temperature, Geochem. Int., 44, 1243-1245, 2006.

Peng, Z. and Ben-Zion, Y.: Temporal changes of shallow seismic velocity around the Karadere-Duzce branch of the north Anatolian fault and strong ground motion, Pure Appl. Geophys., 163, 567-600, 2006.

Peters, M. I. and Reimanis, I. E.: Grain boundary grooving studies of yttrium aluminum garnet (YAG) bicrystals, J. Am. Ceram. Soc., 86, 870-872, 2003.

Rabkin, E., Klinger, L., Izyumova, T., Berner, A., and Semenov, V.: Grain boundary grooving with simultaneous grain boundary sliding in Ni-rich NiAl, Acta Mater., 49, 1429-1438, 2001.

Rabkin, E., Gabelev, A., Klinger, L., Semenov, V., and Bozhko, S.: Grain boundary grooving in molybdenum bicrystals, J. Mater. Sci., 41, 5151-5160, 2006.
Rimstidt, J. D. and Barnes, H. L.: The kinetics of silica-water reactions, Geochim. Cosmochim. Ac., 44, 1683-1699, 1980.

Robertson, W. M.: Grain-boundary grooving by surface diffusion for finite surface slopes, J. Appl. Phys., 42, 463-467, 1971.

Saylor, D. M. and Rohrer, G. S.: Measuring the influence of grainboundary misorientation on thermal groove geometry in ceramic polycrystals, J. Am. Ceram. Soc., 82, 1529-1536, 1999.

Schlegel, M. L., Nagy, K. L., Fenter, P., and Sturchio, N. C.: Structures of quartz (10-10) and (10-11)-water interfaces determined by X-ray reflectivity and atomic force microscopy of natural growth surfaces, Geochim. Cosmochim. Ac., 66, 3037-3054, 2002.

Schutjens, P. M. T. M.: Experimental compaction of quartz sand at low effective stress and temperature conditions, J. Geol. Soc. Lond., 148, 527-539, 1991.

Siggia, E. D.: High rayleigh number convection, Annu. Rev. Fluid Mech., 26, 137-168, 1994.

Smith, D. L. and Evans, B.: Diffusional crack healing in quartz, J. Geophys. Res., 89, 4125-4135, 1984.

Sotin, C. and Poirier, J. P.: Analysis of high-temperature creep experiments by generalized nonlinear inversion, Mech. Mater., 3, 311-317, 1984.

Suzuki, S. and Kuroiwa, D.: Grain-boundary energy and grainboundary groove angles in ice, J. Glaciol., 11, 265-277, 1972.

Tenthorey, E., Cox, S. F., and Todd, H. F.: Evolution of strength recovery and permeability during fluid-rock reaction in experimental fault zones, Earth Planet. Sc. Lett., 206, 161-172, 2003.

Tester, J. W., Worley, W. G., Robinson, B. A., Grigsby, C. O., and Feerer, J. L.: Correlating quartz dissolution kinetics in pure water from $25^{\circ} \mathrm{C}$ to $625^{\circ} \mathrm{C}$, Geochim. Cosmochim. Ac., 58, 24072420, 1994.

Thompson, C. V.: Grain growth in thin films, Annu. Rev. Mater. Sci., 20, 245-268, 1990.

Urai, J. L., Williams, P. F., and van Roermund, H. L. M.: Kinematics of crystal growth in syntectonic fibrous veins, J. Struct. Geol., 13, 823-836, 1991.

Wagner, W. and Pruß, A.: The IAPWS formulation 1995 for the thermodynamic properties of ordinary water substance for general and scientific use, J. Phys. Chem. Ref. Dat, 31, 387-535, 2002.

Watson, E. B. and Wark, D. A.: Diffusion of dissolved $\mathrm{SiO}_{2}$ in $\mathrm{H}_{2} \mathrm{O}$ at $1 \mathrm{GPa}$, with implications for mass transport in the crust and upper mantle, Contrib. Mineral. Petrol., 130, 66-80, 1997.

Weill, D. F. and Fyfe, W. S.: The solubility of quartz in $\mathrm{H}_{2} \mathrm{O}$ in the range $1000-4000$ bars and $400-550^{\circ} \mathrm{C}$, Geochim. Cosmochim. Ac., 28, 1243-1255, 1964.

Xie, Z. and Walther, J. V.: Quartz solubilities in $\mathrm{NaCl}$ solutions with and without wollastonite at elevated temperatures and pressures, Geochim. Cosmochim. Ac., 57, 1947-1955, 1993.

Zhang, W., Sachenko, P., and Schneibel, J. H.: Kinetics of thermal grain boundary grooving for changing dihedral angles, J. Mater. Res., 17, 1495-1501, 2002.

Zhang, W., Sachenko, P., and Gladwell, I.: Thermal grain boundary grooving with anisotropic surface free energies, Acta Mater., 52, 107-116, 2004. 